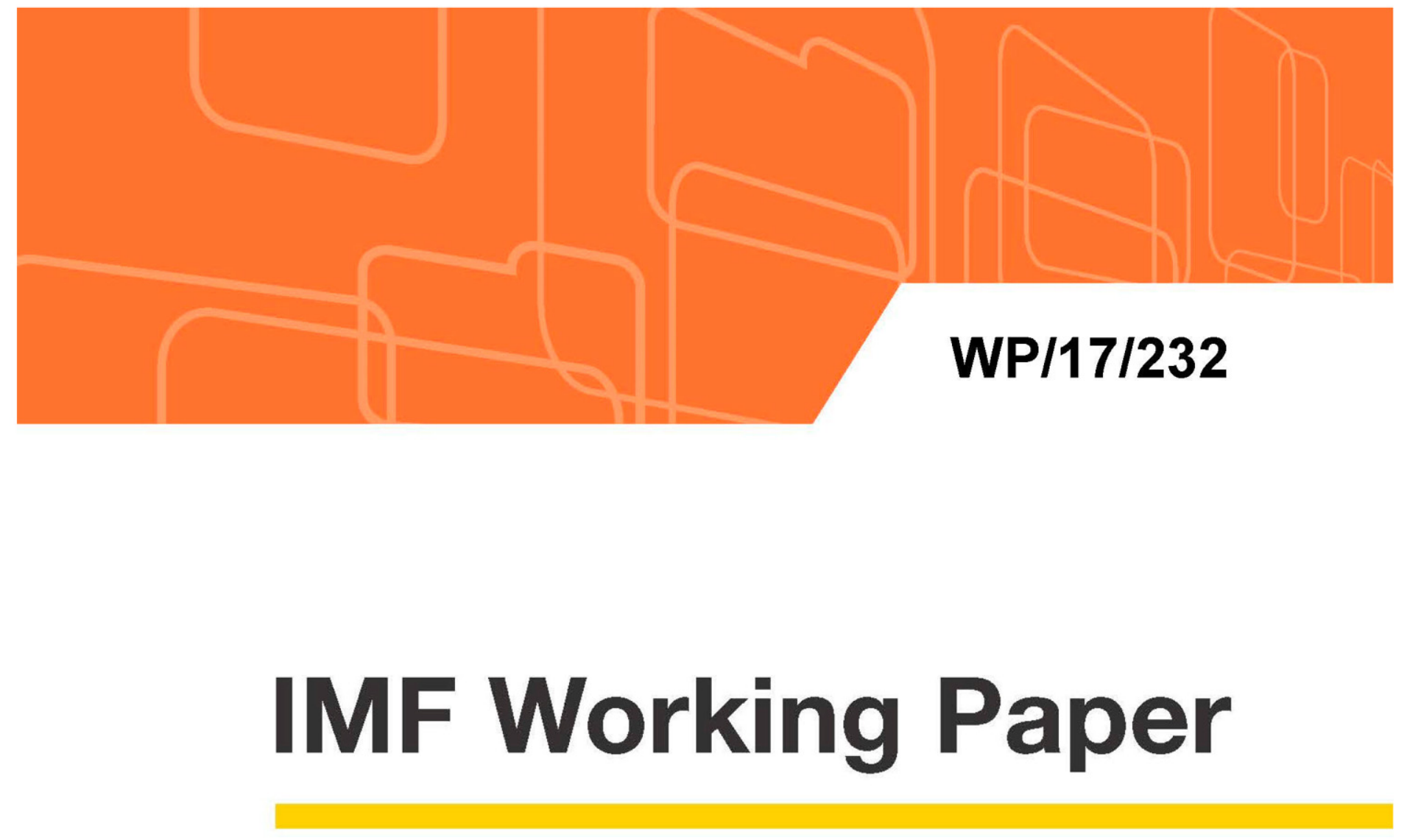

\title{
The Global Banking Network in the Aftermath of the Crisis: Is There Evidence of De-globalization?
}

by Eugenio Cerutti and and Haonan Zhou

IMF Working Papers describe research in progress by the authors and are published to elicit comments and to encourage debate. The views expressed in IMF Working Papers are those of the authors and do not necessarily represent the views of the IMF, its Executive Board, or IMF management. 


\section{WP/17/232}

\section{IMF Working Paper}

\section{The Global Banking Network in the Aftermath of the Crisis: Is There Evidence of De-globalization?}

by Eugenio Cerutti and and Haonan Zhou

IMF Working Papers describe research in progress by the authors and are published to elicit comments and to encourage debate. The views expressed in IMF Working Papers are those of the authors and do not necessarily represent the views of the IMF, its Executive Board, or IMF management.

$$
\text { I N T E R N A T I O N A L M O N E T A R Y F U N D }
$$




\title{
IMF Working Paper
}

Research Department

\section{The Global Banking Network in the Aftermath of the Crisis: \\ Is There Evidence of De-globalization? \\ Prepared by Eugenio Cerutti and Haonan Zhou*}

Authorized for distribution by Maurice Obstfeld

November 2017

\begin{abstract}
IMF Working Papers describe research in progress by the authors and are published to elicit comments and to encourage debate. The views expressed in IMF Working Papers are those of the authors and do not necessarily represent the views of the IMF, its Executive Board, or IMF management.
\end{abstract}

\begin{abstract}
Post-crisis dynamics show a shrinkage in the overall amount of cross-border bank lending, which has been interpreted in the literature as a retreat in financial globalization. In this paper, we argue that aggregate figures are not sufficient to support such a claim in terms of the overall structure of the global banking network. Based on a systematic approach to measuring, mapping and analyzing financial interconnectedness using network theory, we show the global banking network has evolved, but it has not undergone a generalized retrenchment in financial linkages. Moreover, some parts of the network are currently more interlinked regionally than before the crisis, and less dependent on major global lenders.
\end{abstract}

JEL Classification Numbers: F34, F36, F39, G15.

Keywords: Cross-border Lending, Banking Network, Financial Interconnectedness.

Authors’ E-Mail Address: ECerutti@imf.org, HZhou@imf.org

\footnotetext{
${ }^{*}$ Cerutti and Zhou are at Research Department, International Monetary Fund, 700 19th Street NW, Washington D.C. 20431. We are grateful to Abdul Abiad, Tamin Bayoumi, John Bluedorn, John Caparusso, Stijn Claessens, Rodrigo Cubero, Anna Ilyina, Yevgeniya Korniyenko, Robin Lumsdaine, Maury Obstfeld, Thierry Tressel, and participants of the Bank Negara Malaysia-IMFER conference "Threats to Globalization in the Aftermath of the Crisis", Bank of Mexico conference "Network Models and Stress Testing for Financial Stability", and a seminar at the IMF for helpful comments, and to Paola Ganum for help with the data from the RES Bank Contagion Module. Authors' E-Mail addresses: ecerutti@imf.org; hzhou@imf.org. The opinions expressed herein are solely the responsibility of the authors and should not be interpreted as reflecting those of the IMF, its Executive Board, or IMF management.
} 


\section{Contents}

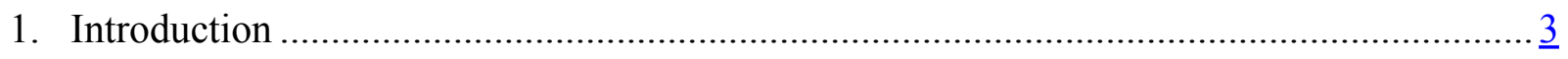

2. Building and Analyzing the Network: Data and Measures .................................................. $\underline{6}$

2.1. Mapping and Measuring Cross-Border Banking Flows ………………………...... $\underline{6}$

2.2. Network Analysis: Choosing the Right Tools ……………...................................

3. Understanding Cross-Border Banking Linkages: Results from Network Analysis ...............15

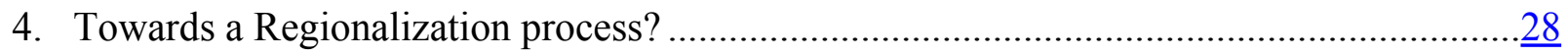

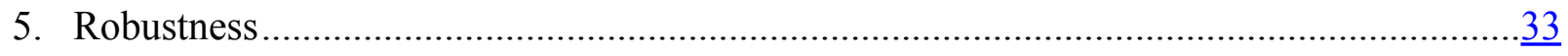

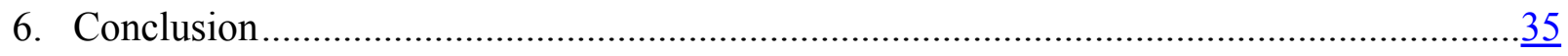

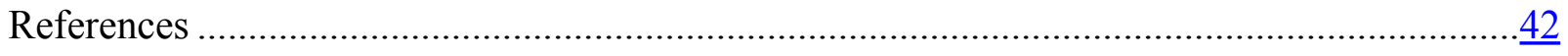

\section{Tables}

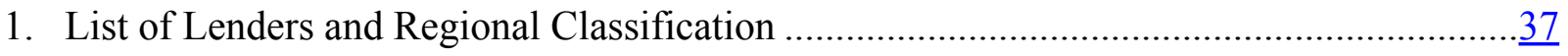

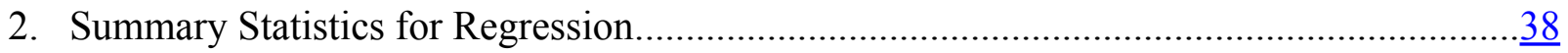

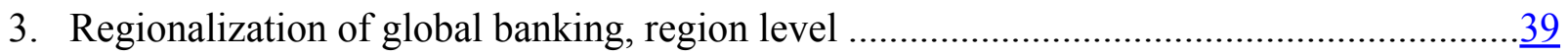

4. Regionalization of global banking ……………….......................................................

5. Cross-Dataset Comparison: Correlation of Network Measures …………………………....41

\section{Figures}

1. Aggregate Global Cross-Border Claims........................................................................

2. Illustration of LBS, CBS and adjusted CBS measures using networks ............................. $\underline{8}$

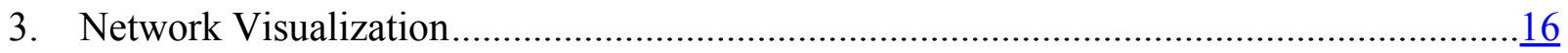

4. Evolution of Degree, Strength and Concentration .......................................................

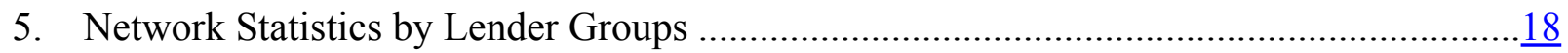

6. In-Degree Distribution ..........................................................................................

7. Mean Katz-Bonacich Centrality by Country Groups ………….......................................19

8. Mean Authority/Hub Measure by Country Groups.........................................................

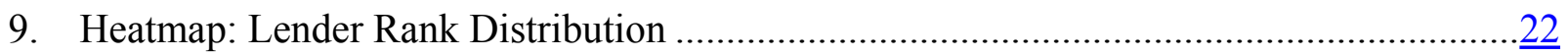

10. Heatmap: Regional Key Players Rank Distribution..........................................................

11. Evolution of Average Out-Degree and Out-Strength by Lender Tier.................................

12. Deposit-Loan Ratio: Cross-Sectional Distribution..............................................................

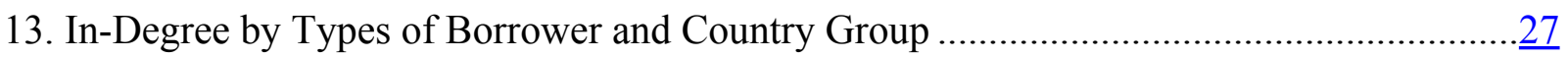

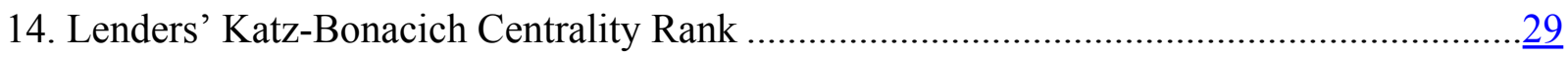

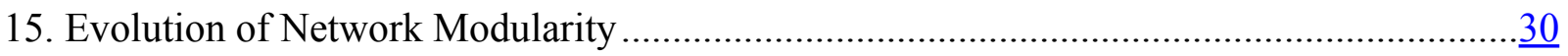

16. Latin-America: Within-Region Banking Flows ……………………............................

17. In-Degree and In-Strength: Alternative Data ..............................................................

18. Average Degree and Strength: Alternative Measure......................................................... 


\section{Introduction}

The global financial crisis in 2008-09 underscores the unique role of financial interconnectedness in transmitting and propagating adverse shocks. Previous literature, starting from the seminal Allen and Gale (2000), which stresses the significance of network structure in generating contagion, and Kiyotaki and Moore (2002), which lays out detailed mechanisms of contagion through balance-sheet effects, is followed by a large body of theoretical and empirical research on interbank markets, mostly within a single country or region, that focuses on modeling banks' behavior in response to shocks in the financial system. Cross-border implications of the banking network, however, are mostly ignored due to scarcity of data and rich country-level heterogeneity that may lower the explanatory power of a unified framework.

The sharp fall in global cross-border banking claims after the crisis has been persistent, either measured in Bank for International Settlements (BIS) Locational Banking Statistics (LBS) or BIS Consolidated Banking Statistics (CBS), as shown in Figure 1. This persistent aggregate decline in cross-border banking claims has been considered evidence of financial deglobalization (e.g.; Lund et al 2013; Forbes 2014; Mallaby 2016; and Forbes, Reinhardt, and Wieladek 2017). In this paper, we consider the validity of the financial de-globalization argument by studying the evolution of the global banking network before, during and after the crisis, with a particular focus on the aftermath of the crisis. Instead of trying to establish the role of the network in propagating the crisis at a global level, we take the role of the global banking network as given and seek to investigate the impact of the crisis on the network. In this context, our key contributions to the literature are twofold: (i) we measure and map the global banking network using a model-free and data driven approach; and (ii) we analyze the evolution of the network using network analysis tools, including some novel applications, that are relevant given the characteristics of the global banking network and the available data.

The foremost challenge in constructing the global banking network is to map and identify an accurate and comprehensive network structure using the available data on cross-border banking flows. Researchers face a tradeoff between data coverage and frequency. Highfrequency data, such as banks' daily transactions, often contain a limited number of banks within a country, while datasets with a good coverage of global lending mainly report country-level aggregate statistics, and are updated infrequently. This challenge is further complicated by the difficulty in identifying the composition, sources and destinations of bank flows, primarily due to the use of offshore financial centers as important financial intermediaries. Not only are global banks able to conduct cross-border lending via entities in their headquarters and offshore financial centers, but also they can lend domestically through subsidiaries and/or branches within the border of the borrower countries. BIS International Banking Statistics (IBS), through its two datasets (LBS and CBS), offer the best available data to map the international bank lending activity across countries. This is especially the case of the CBS dataset, which consolidates gross claims of each international banking group on borrowers in a particular country, aggregating those claims following the nationality of the parent banks. This nationality-based nature of CBS is an advantage over LBS, which follows a residency-based principle, and thus obscures the linkages between the borrower 
country and the parent bank institution, when lending originates in affiliates located in third countries (e.g., off-shores financial centers). A disadvantage of using CBS is that it registers the full claims of the affiliates, independent of how those assets were funded (e.g., a claim of a foreign affiliate that is fully funded with local domestic depositors is still counted as a claim from the country of the parent bank on the borrower country where the affiliate is located). In order to avoid this overstatement of financial linkages, which are large in the case of emerging countries as shown in the next section, we follow Cerutti (2015) and combine BIS CBS data with bank level data, taking into account the claims of foreign affiliates and the local deposit funding used by subsidiaries and branches.

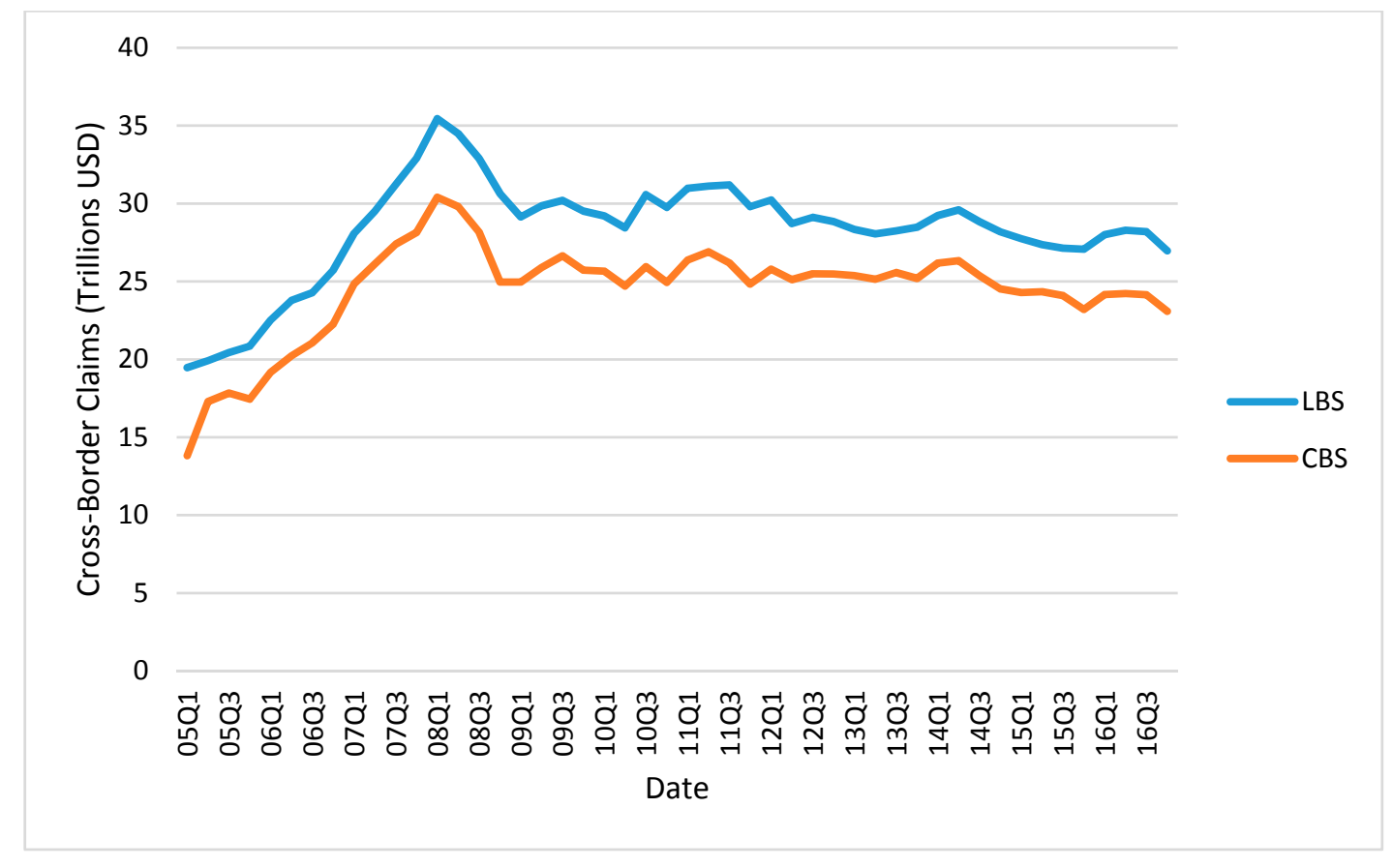

Figure 1. Aggregate Global Cross-Border Claims

Source: BIS Locational and Consolidated Banking Statistics

We use the improved measure of cross-border banking linkages to construct a sequence of global banking networks, and apply tools from network theory to analyze the evolution of economic and structural properties of the network. Following the example of Borgatti (2005), which highlights that some centrality measures do not provide economic insight in some networks, we take a step further to incorporate this important discussion into our choice of metrics to identify important players and trace the structural evolution of the global banking network. We provide an in-depth discussion of network measure choice based on the structural context of a core-periphery, asymmetric and unbalanced network structure and in the economic context of characterizing banking flows at the country level. We introduce measures of node importance that capture distinct aspects of global banking linkages. In particular, we use recursively defined Katz-Bonacich centrality (see Katz (1953) and Bonacich (1987)) and authority/hub measure (Klienberg, 1999) to characterize country importance based on its connection to and dependence on other important countries, as well as a novel application of modularity à la Newman and Girvan (2004) in order to capture the 
regional fragmentation of the network. The flexibility of our network configuration allows us to use a small number of network metrics to reveal distinct aspects of network structure and node importance.

We find that the overall shrinkage of cross-border bank lending after the crisis, which has been the key argument behind the claims on financial de-globalization, is also reflected in the average number of links and their strength in the global banking network. However, rich details on the evolution of the network suggest that this argument is overly simplified. While connections within traditional major global lenders (banks in France, Germany, Japan, UK, and US) became sparser, many non-reporting countries located at the periphery of the network are more connected, mainly due to the rise of non-major global lenders out of Europe. Measured in metrics of node importance, these lenders have been steadily climbing up the rank, resulting in a corresponding decline of European lenders in status and borrowers' decreasing dependence on traditional lending countries. Moreover, we find substantial evidence indicating increasing level of regionalization of the global banking network. Even though post-crisis retrenchment of major global and non-major European banks' operation in the aggregate was just partially offset by the rest of the BIS reporting countries' regional expansion, their targeted expansions have increased regional interlinkages through both direct cross-border and affiliates' lending. More formally, using network modularity as a novel application to assess the quality of network cluster structure based on region divisions, we find that this measure increases after the crisis, thus indicating, from the perspective of network theory, that some form of regionalization characterizes the post-crisis dynamics of the global banking network. Finally, we also confirm this regionalization process through a regression analysis of the evolution of cross-border lending. After controlling by geographical distance and trade relationships as well as lender and borrower characteristics, we find a statistically significant increase in cross-border lending when both borrower and lender belong to the same region, especially in the case of peripheral lenders during the post-crisis period.

Our article relates to two main strands of research. The first and closest strand includes a few number of empirical studies mapping international bank activities at a worldwide level. A key reference in this group is Minoiu and Reyes (2013), which uses LBS data to conduct a heuristic global banking network analysis at country level during 1978-2010. Their study finds that the crisis brings about a severe shock to the global banking network structure, but does not have sufficient data to reveal post-crisis dynamics. Chinazzi et al (2013) performs similar cross-country analysis from the perspective of international portfolio debt investment flows using CPIS data during 2001-2010. They highlight that while the crisis has induced changes in the topology of the financial network and in the evolution of its statistical properties, the overall core-periphery, disassortative (nodes do not tend to attach to similar nodes) nature of the architecture remains stable. Using bank level data on syndicated loans, Hale (2012) and Hale, Kapan, and Minoiu (2016) stress the importance of interbank connectedness in transmitting shocks related to the crisis among banking network players. In this context, in addition to characterizing the evolution of the global banking network using adjusted CBS data, we offer a novel comparison of the same network constructed with different BIS datasets. We find that while the networks based on LBS share similarity in aggregate dynamics with those based on CBS, the former double-counts lending within 
financial institutions from the same banking group, exaggerating the role of key financial intermediaries such as offshore financial centers.

A second strand of papers focuses on the evolution of the foreign affiliates of international banking groups during the crisis. This is especially the case of Claessens and Van Horen (2015), which analyzes the evolution of international bank affiliate structures during the period 2007-2013. They show that, even though there was some net retrenchment in foreign bank presence at the aggregate level after the crisis (especially in crisis-affected western European banks), global banking did not become more fragmented, but rather went through some important structural transformations with a greater variety of players and a more regional focus. This rise in regional financial integration is also documented in Bank for International Settlement (2014) and extensively in International Monetary Fund (2017) for Latin America. Our analysis of the global banking network, especially the breakdown between direct cross-border claims and affiliate (local) claims, goes in the same direction and helps put them into context. Despite the fact that direct cross-border lending declined more than local lending during the crisis (see Cerutti and Claessens, 2017), the importance of direct cross-border lending in terms of number of linkages and their strength is still larger than the ones generated by foreign affiliates' lending (either with or without the adjustment of affiliate claims by domestic deposit funding). Moreover, despite heterogeneity, our results highlight that peripheral borrower countries that are currently more interlinked regionally than before the crisis, benefited from stronger linkages with non-major, non-European lenders, in terms of both direct cross-border lending and affiliates' claims. This result is robust when we include domestic deposit funding into the calculation of local claims.

The rest of this paper is organized as follows. Section 2 outlines our methodology to identify the global banking from data and deal with data issue. Section 3 provides the results of our explorative analysis using network analysis tools. Section 4 presents modularity measures as well as regressions focusing on the presence a regionalization process. Section 5 includes robustness checks and cross-dataset comparison, and, finally, Section 6 concludes summarizing the policy conclusions, which are not minor since they indicate that the global banking network has evolved, but it has not undergone a generalized retrenchment in financial linkages.

\section{Building and Analyzing the Network: Data and Measures}

This section outlines our methodology to map the global banking network as well as the network tools best suited for its analysis.

\subsection{Mapping and Measuring Cross-Border Banking Flows}

We use the following general guidelines for mapping and measuring the linkages among countries:

A) Model free and data driven: Except for a few economically plausible restrictions, our construction is model-free and data-driven. We do not impose any underlying 
data-generating process or distribution of links, nor do we perform simulation of network based on strong assumptions.

B) Directed flows: We consider bank lending as a flow variable, so that the network of cross-border lending is directed (from lender to borrower).

C) Nationality based measure: More importantly, the network should reflect the actual interconnectedness among countries, so as to generate any risk-related implication. A nationality-based approach is typically superior to residence-based, as bilateral financial flows, like trade flows, do not necessarily stop their transmission at the intermediate nodes (e.g., off-shore centers). Thus, the latter measure may not reflect the ultimate receiver of financial risk.

\section{Data used}

To build the global banking network, we use both publicly-available and restricted bilateral cross-border exposure from BIS International Banking Statistics (IBS). BIS publishes two datasets capturing global banking activities. The Location Banking Statistics (LBS) records the cross-border positions and the local positions in foreign currencies of banks located in a particular country on an unconsolidated basis. On the other hand, the Consolidated Banking Statistics (CBS) tracks the consolidated gross claims of each international banking group, aggregating following the nationality of the parent bank. Thus, the CBS is better when analyzing the transition of risks within the network as well as for avoiding the overstating of some linkages due to its residency-based nature.

In this context, we use CBS to prevent overstating the role of some intermediate nodes such as offshore financial centers. Nonetheless, CBS could overstate linkages for countries with strong presence of foreign bank affiliates, since CBS include the claims of foreign affiliates, whose assets may be funded by a substantial amount of local deposits. ${ }^{1}$ These aspects are illustrated in Figure 2, which presents the 2006Q1 cross-country exposure network for United States, Brazil, Spain, Mexico and a set of offshore financial centers (Cayman Islands, Bahamas and Bermuda), plotted using LBS, CBS and adjusted CBS separately. Figure 2a compares LBS with CBS data. While LBS heavily overstates the cross-border exposure between United States, Cayman Islands and Bahamas, CBS data corrects for this bias. Reflected in the data, US banks' claims on Cayman Islands and Bahamas borrowers is, respectively, 33 times and 75 times larger when using LBS than when using CBS. This issue with LBS data, moreover, is not restricted to lender-offshore pairs only, given that within banking group transactions between different countries are not consolidated.

Following Cerutti (2015), we supplement CBS data with bank-level balance sheet data from Bankscope, and calculate inter-country linkages as the upstream exposure of borrower $j$ to lender (reporting country) $i, U_{i j}$, defined as follows:

\footnotetext{
${ }^{1}$ Detailed comparisons of BIS LBS and CBS data can be found in Committee on the Global Financial System (2012) and Cerutti, Claessens, and McGuire (2014).
} 


$$
U_{i j}^{\text {adjusted }}=C B_{i j}+L C_{i j} \times\left[1-\min \left(D L R_{i j}, 1\right)\right]
$$

where $C B_{i j}$ represent cross-border claims of country $i$ to country $j, L C_{i j}$ measures affiliate (local) claims. $D L R_{i j}$, deposit loan ratio of lender-borrower pair, is calculated from

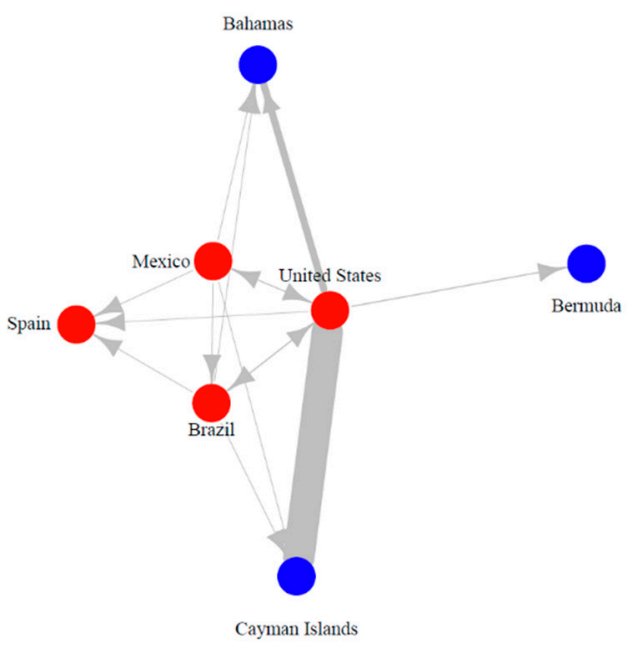

LBS: Offshore positions are large

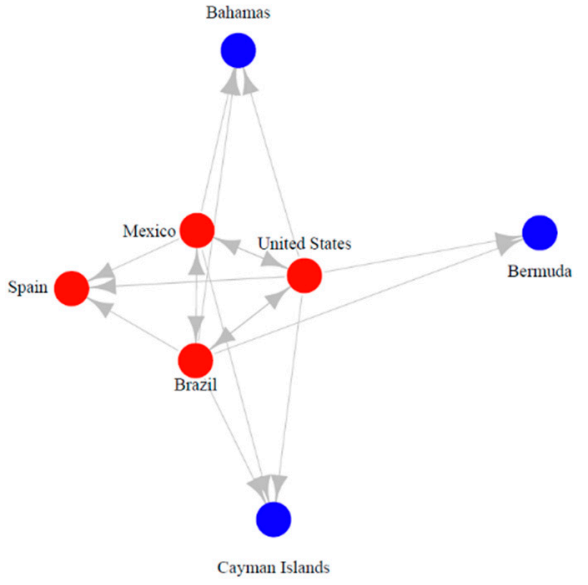

CBS and Adjusted CBS:

Offshore centers get smaller role in networks.

(a)

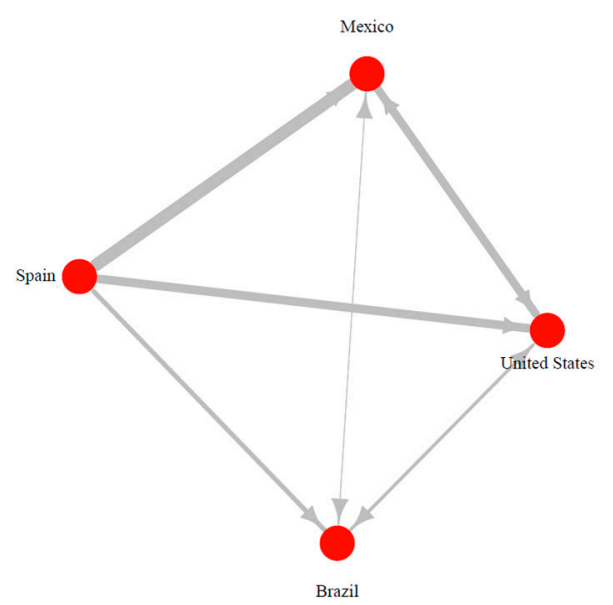

CBS: Local claims include domestic funding

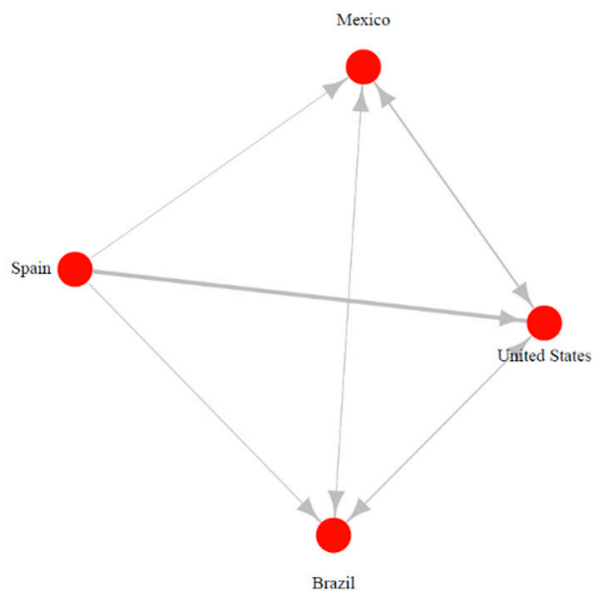

Adjusted CBS:

Local claims are scaled down by deposit-loan ratio.

(b)

\section{Figure 2. Illustration of LBS, CBS and adjusted CBS measures using networks}

Note: Figure 2a plots cross-border lending in 2006Q1 using both BIS Locational Banking Statistics (LBS) and Consolidated Banking Statistics (CBS) adjusted using the methodology of Cerutti (2015). Edge width is proportional to level of exposure and scaled to facilitate visualization. Nodes in red represents BIS reporting countries. For LBS, bilateral cross-border claim data from Spain are not publicly available until 2014Q1, and are thus omitted from the networks. 


$$
D L R_{i j}=\frac{\sum_{\text {Subsidiaries from } i} \operatorname{deposits}_{i j}^{\text {Subsidiaries }}+\sum_{\text {Branches from } i} \operatorname{deposits~}_{i j}^{\text {Branches }}}{\sum_{\text {Subsidiaries from } i} \operatorname{loan}_{i j}^{\text {Subsidiaries }}+\sum_{\text {Branches from } i} \operatorname{loan}_{i j}^{\text {Branches }}}
$$

Compared with ultimate-risk CBS foreign claims, expressed as the sum of cross-border claims and local claims, the new measure adjusts the share of local claims in the total foreign claims by a factor of $1-\min \left(D L R_{i j}, 1\right)$, as a proxy for the proportion of loans not financed by local consumer deposits. The direct cross-border claims component, $C B_{i j}$, is not adjusted, as it is fully funded by foreign (parent bank) resources. Figure $2 \mathrm{~b}$ presents the cross-border exposure network between four BIS reporting countries. A substantial proportion of local claims for Spanish branches in the other three reporting countries are funded with domestic deposits, and such overestimation has been corrected in the adjusted CBS data. In fact, claims of Spanish banks to US, Brazil and Mexico using CBS data is, respectively, 2, 4, and 16 times larger than when measured by adjusted CBS data.

\section{Network Construction}

We used the improved measure of cross-border exposure to construct the global banking network $^{2}$. Our final dataset contains 45 quarters of adjusted BIS CBS data from 2005Q1 to 2016Q2, with detailed cross-border exposure on 29 BIS reporting countries and over 160 non-reporting countries ${ }^{3}$. Table 1 lists all reporting countries in our sample, and their respective classifications. This classification, based on aggregate statistics and geographic location of each lender, is not restrictive. Five major global lenders (United States, United Kingdom, France, Germany and Japan) are consistently among the top-five in total claims during our sample period. We shall show, in Section 3, that our node-level importance statistics confirm the validity of this assignment of lenders into groups. For each quarter $t$, we create our network as follows. Let $i, j$ be one pair of countries (referred to as "nodes" in network terminology). Define the adjacency matrix, $\mathbf{A}_{t}$, to be a non-symmetric, nonstochastic matrix, whose entry, $A_{i j t}$, denotes the non-negative cross-border banking flow from country $i$ to country $j$ at time $t^{4}$. Formally, the flow is defined as

$$
A_{i j t}:=\max \left(\Delta_{4} U_{i j t}^{\text {adjusted }}, 0\right)=\max \left(U_{i j t}^{\text {adjusted }}-U_{i j(t-4)}^{\text {adjusted }}, 0\right)
$$

$\mathbf{A}_{t}$ represents a network structure, $\mathbf{N}_{t}$, which we refer to as the "baseline" network. In network terms, $\mathbf{N}_{t}$ is directed and weighted. Several observations are immediate. First, the

\footnotetext{
${ }^{2}$ Here, the baseline data is not adjusted for structural breaks and exchange rate variation. We compare the shorter, adjusted version of the data with the baseline results in Section 5.

${ }^{3}$ The exact number of non-reporting countries vary from 164 to 166 , In particular, we take account of the changes in country composition after the dissolution of Serbia and Montenegro.

${ }^{4}$ A net decrease in bilateral exposure may include net repayment, which we leave for future research.
} 
network has, by construction, a core-periphery structure ${ }^{5}$, with BIS reporting countries act as core nodes and non-reporting countries as peripheries (we may use the term "lenders/borrowers" and "reporting/non-reporting countries" interchangeably in our subsequent analysis). The network construction restricts the directionality of edges: only core countries can send out links, since $A_{i j t} \equiv 0$ if $i$ is a non-reporting country. For a directed network, a path is a sequence of directed edges that connect two nodes. A geodesic path is a path connecting two nodes and has the shortest length. As a result of the directionality restriction per our construction, the maximum length of a geodesic path from a core country to any other country is two, and there is no path from peripheral countries to core countries, nor does there exist a path between two peripheries. Admittedly restrictive, this configuration is consistent with Hale, Kapan, and Minoiu (2016), which establishes the role of both direct (first-degree) and indirect (second-degree) exposure in explaining shock transmission in banking networks. Moreover, this configuration is completely data-driven and gives a better characterization of global cross-border lending than assuming specific processes of network generation. In Section IV, we show that the general properties of our network are robust under defining banking flows alternatively or explicitly correcting for break-in-series and exchange rate variation during crisis.

For some network measures to be introduced in the next section, we work with an alternative version of the global banking network. Let $\mathbf{A}_{t}^{*}$ be the adjacency matrix of the network $\mathbf{N}_{t}^{*}$, referred to as the "share" network, which serves better to study credit-borrower dependence. By construction, $\mathbf{A}_{t}^{*}$ is stochastic, but still non-symmetric. Each entry of $\mathbf{A}_{t}^{*}$ represents the cross-border bank flow from country $i$ to country $j$ as the share of total non-negative crossborder bank flow to country $j$. Formally, $A_{i j t}^{*}=\frac{A_{i j t}}{\sum_{i} A_{i j t}}$.

\subsection{Network Analysis: Choosing the Right Tools}

Basic Structural Indicators: The first step to characterize the network is to investigate its global structural property. We calculate node degree, strength and Herfindahl-Hirschman Index and use the first moments as structural indicators of the network. ${ }^{6}$ The degree and strength of a node are among the fundamental measures of node-level connectedness in a network. Node degree is the number of links passing through each node. Node strength can

\footnotetext{
${ }^{5}$ Core-peripheral structure refers to a network structure with a dense "core" and an outlying, loosely-connected "periphery". See Zhang, Martin and Newman (2015) for a discussion. It is not to be confused with our definition of "major global lenders", which underscore the central role of lenders from France, Germany, Japan, UK, and US .

${ }^{6} \mathrm{We}$ also calculate network density, defined as the ratio of the number of edges to the number of possible edges, as a global measure of network. This measure turns out to be quantitatively similar with mean degree, as the network comes with an almost constant node composition with restrictions on its core-periphery structure. Instead of calculating local clustering coefficients, as past studies often do, we argue that this measure may not be as useful, due to the fact that 1) our core-periphery configuration restricts the type of triad structures the network can formulate; 2) the similar dynamics of clustering coefficient with degree and strength extract no more information from the network; 3) at the country level, formulation of higher-order structures may only be incidental and does not represent economically meaningful flows.
} 
be interpreted as the weighted version of node degree, such that the strength of a node is the total weight of links passing through it. In our network, node strength represents the total borrowing/lending a country receives/sends. For a directed network, we can define the indegree, $d_{i}^{\text {in }}$ and out-degree, $d_{i}^{\text {out }}$ respectively as the number of links incoming and departing from node $i$. The in-strength, $s_{i}^{\text {in }}$ and out-strength, $s_{i}^{\text {out }}$ can be similarly defined. Using our notation, these measures are given by $d_{i t}^{i n}=\sum_{j \neq i} \mathbf{1}_{A_{i j t}>0}, d_{i}^{o u t}=\sum_{j \neq i} \mathbf{1}_{A_{j i t}>0}, s_{i t}^{i n}=\sum_{j \neq i} A_{i j t}$, $s_{i t}^{\text {out }}=\sum_{j \neq i} A_{j i t}$. To characterize the overall global property of the network using degree and strength, we calculate its mean degree and strength. The denominator for mean "out" measures is adjusted to be the number of reporting countries in our sample.

We supplement the structural indicators introduced above with Herfindahl-Hirschman Index (HHI), the classic measure of market concentration in industrial organization literature. We distinguish between in-HHI, as the sum of lenders' squared shares in each borrower's total inflows (in-strength), and out-HHI, as the sum of borrowers' squared shares in each lender's total outflows (out-strength). Node HHI, used in Minoiu and Reyes (2013) and Chinazzi et al (2013) for global banking and financial networks, indicates the level of diversification for each country as either lender or borrower, and may thus reflect the country's vulnerability to negative shocks due to excessive dependence to its counterparties.

Measures of Node Importance: Structural significance of nodes in a network can be characterized by node-level measures of importance, known as centrality-like measures. Apart from basic metrics such as degree and strength (they belong broadly to the group of centrality measures), we discuss the appropriateness of applying a variety of centrality-like measures to the analysis of country importance in the global banking network.

First, it is useful to illustrate of the notion of importance in a country-level banking network. von Peter (2007) uses traditional centrality measures to characterize international banking centers. A country is considered a global banking hub if it is well connected overall, well positioned relative to other countries, and well connected to important counterparties. ${ }^{7}$ Recent literature interprets centrality measures and node importance from the perspective of systemic risk, such that a measure combining multiple network centralities could serve as good measurement of the systemic risk of each network player. Martinez-Jaramillo et al (2014) applies Principal Component Analysis (PCA) to a family of six centrality measures to generate a heuristic measure of systemic risk for Mexican banking system's payment and exposure network.

We adopt the above interpretations with qualification. The core-periphery structure and directionality restriction inherent in the networks herein analyzed serve as the major structural constraint when selecting appropriate centrality measures. Two traditional

\footnotetext{
${ }^{7}$ The first and third points are captured by our choice of centrality measures. Our measures do not take into account the second point, as global banking flow might not necessarily traverse on the shortest paths. This concept is captured by closeness and betweenness centrality, not applicable to our network configuration. See footnote 8 for details.
} 
centrality measures, closeness and betweenness centrality, are thus not appropriate to be included in our analysis. ${ }^{8}$ These measures turn out to be ineffective in characterizing the systemic importance of peripheral countries: due to restrictions on core-periphery geodesic length and direction of edges, peripheral countries share similar closeness centralities and have zero betweenness centralities. Unlike the transmission of an infectious disease, global banking flow processes do not necessarily prefer to traverse the network via the shortest path, measured either by geographical distance or length of edges. Otherwise, we would observe strong regional clusters, and the role of offshore financial centers as global financial intermediaries would be further downplayed. The general property of cross-border lending, therefore, echoes graph-theoretic literature (Borgatti, 2005) and serves as an empirical observation against the use of geodesic-based centrality measures in our analysis.

On the other hand, using centrality measures to proxy for systemic risk requires support from economic theory, which previous literature tends to neglect. Blending various measures using dimension-reduction methods such as PCA further exacerbates this concern. Although one single risk measure could serve as a succinct policy-making reference, economic interpretation for this heuristic measure tends to be vague. Moreover, as is argued below, well-constructed centrality measures are able to illustrate country-level systemic risk from multiple distinct perspectives. While we do not seek to equate node-importance measures with risk measures due to the data constraint, such measures still reflect the dynamics of individual countries in the global banking system. We keep the number of node importance measures to a minimum, with each measure justified by the literature and capable of extracting distinct information. In this context, we introduce below two sets of measures that characterize node importance in the global banking network. These measures fully reflect the criteria of key players in the network, that a country's importance is determined by its relative position, i.e. its connections to important counterparties.

Katz-Bonacich Centrality. We use Katz-Bonacich centrality to examine the structural importance and risk level of each country in our sample. Katz-Bonacich centrality takes into account the counterparties of nodes' connections when measuring node importance. Formally using our notation, the Katz-Bonacich centrality of node $i$ at time $t$, denoted by $x_{i t}$, is given by

$$
x_{i t}=\alpha_{t} \sum_{j} A_{j i t} x_{j t}+\beta_{i t}
$$

where $\alpha_{t}$ is an attenuation constant and $\beta_{i t}$ represents a positive exogenous component, independent of network structure. To compute Katz-Bonacich centrality, observe that in matrix notation:

$$
\mathbf{x}_{t}=\left(I-\alpha A_{t}^{T}\right)^{-1} \boldsymbol{\beta}
$$

\footnotetext{
${ }^{8}$ Closeness centrality is defined as the inverse of the "distance" from one node to the other locations, where the distance refers to the length of the shortest path (geodesic). Betweenness centrality is similarly defined based on geodesics: calculated as the frequency with which a node lies on the geodesic between two unconnected nodes.
} 
With this formulation, a node has a high Katz-Bonacich centrality if it receives links from other nodes with high Katz-Bonacich centrality. This interpretation illustrates the notion that entities connected to systematically important entities in the network are vulnerable to the transmission of negative shocks hitting important entities first. To calculate KatzBonacich centrality, we control the attenuation factor $\alpha_{t}$ such that $0<\alpha_{t}<\lambda_{1}^{-1}$, where $\lambda_{1}$ is the largest eigenvalue of the normalized adjacency matrix $\hat{A}_{t}$, whose entries, $\hat{A}_{i j}$, are defined to be country $i$ 's cross-border lending to country $j$ as a share of total global crossborder borrowing $\left(\sum_{i, j} A_{i j}\right) .{ }^{9}$ Our final Katz-Bonacich centrality measure is calculated by applying its definition, replacing the adjacency matrix with the normalized matrix $\hat{A}_{t} \cdot{ }^{10}$ Due to the unbalanced, long-tailed nature of the global banking network, for each period $t$ we further normalize this measure by calculating its $z$-score. The exogenous component $\beta$ is set to be the vector of one's to stress the importance of endogenous network factors on node importance. Our formulation of Katz-Bonacich centrality is similar to the "prestige" measure in von Peter (2007), which applies the same measure over global banking network similar to our share network, but using LBS dataset.

Literature on social and economic networks has long established the close connection between Katz-Bonacich centrality and economic theory. Ballester, Calvó-Armengol, and Zenou (2006) is among the first to provide a behavioral foundation to this measure, which is connected to the Nash Equilibrium of a network game. Battaglini and Patacchini (2016) applies Bonacich centrality to the resource allocation decision of political interest groups in a contribution game. The definition of Katz-Bonacich centrality also resembles the Leontief inverse structure, analyzed in Acemoglu, Akcigit, and Kerr (2015) as the key element of network effect in a general production network. In financial network literature, notable recent contributions include Denbee et al (2016) and Heipertz, Ranciere, and Valla (2016), explicitly linking Katz-Bonacich centrality with systemic risk in models of bank lending and sectoral balance-sheet contagion ${ }^{11}$. In the spirit of eigenvector centrality, Katz-Bonacich holds an advantage over the former measure due to its ability to accommodate directed networks. ${ }^{12}$ As a result, Katz-Bonacich centrality is

\footnotetext{
${ }^{9}$ The choice of attenuation factor follows graph-theoretical literature (Bonacich and Lloyd, 2001). When $0<\alpha<\lambda_{1}^{-1}$, Katz-Bonacich measure can be formulated as a geometric series of the adjacency matrix, decayed by $\alpha$. As a result, the measure is guaranteed to be non-negative, and has the additional intuition that it takes all indirect exposure into account.

${ }^{10} \mathrm{We}$ work with the normalized adjacency matrix to comply with the eigenvalue restriction and make sure the attenuation factor is reasonably large. In the actual calculation, we fix our attenuation factor to be 0.5 , so that around $50 \%$ of indirect exposure is considered into the measurement of node importance. In Denbee et al (2016), an attenuation factor of 0.5 results in a network multiplier effect of $1 /(1-0.5)=2$, suggesting that onedollar idiosyncratic shock equally spread across all nodes will result in two dollars' shock to aggregate liquidity in the network.

${ }^{11}$ Heipertz, Ranciere, and Valla (2016) develops an empirical balance-sheet contagion equation, whose first order approximation establishes a proportional relationship between sectoral asset returns and Katz-Bonacich centrality. Denbee et al (2016) models bank's liquidity holding as a network game and characterizes its Nash Equilibrium and key risk players using Katz-Bonacich centrality.

${ }^{12}$ Giudici and Spelta (2016) provides a model-based identification of key players in the global banking network using eigenvector centrality.
} 
regarded as the prime measure of country-level importance and connectedness within the entire global banking network.

Authority/Hub Measure. The Klienberg (1999) authority and hub measure is a pair of useful metrics that highlight node importance due to creditor-borrower dependence. Like Katz-Bonacich centrality, authority and hub measure is defined based on the role of counterparties. Two types of central nodes exist in the network: a node is an authority if it is connected to by hubs, and vice versa. As the pair of metrics distinguishes between prominent receivers and senders, authority and hub measure is especially suitable in the analysis of core-periphery networks with clearly defined country groups (reporting and non-reporting).

We apply authority and hub measure to the share network. ${ }^{13}$ Based on the recursive definition of authority and hub in a share network, a node is considered to be "important" in two distinct ways. Either it is an important hub, the principal creditor for a large number of borrowers, or it is an important authority, heavily dependent on its corresponding hub for cross-border funding. This interpretation entails natural risk implications. We anticipate nodes with high authority scores to reside largely on the periphery, with few funding sources, poor diversification and thus higher vulnerability in the case of a negative shock on their hub counterparties. ${ }^{14}$

Formally, let the authority score of node $i$ be denoted as $a u t h_{i}$ and the hub score as $h u b_{i}$, then using our notation, the measures are recursively defined by

$$
\begin{aligned}
& a u t h_{i t}=\alpha_{t} \sum_{j} A_{j i t}^{*} h_{j} b_{j} \\
& h u b_{i t}=\beta_{t} \sum_{j} A_{i j t}^{*} \text { auth }_{j}
\end{aligned}
$$

where $\alpha_{t}, \beta_{t}$ are constants. Combined in matrix notation, the measures are given by

$$
\begin{aligned}
& \lambda_{t} \text { auth }_{t}=A_{t}^{* T} A_{t}^{*} \text { auth }_{t} \\
& \lambda_{t} \mathbf{h u b}_{t}=A_{t}^{*} A_{t}^{* T} \mathbf{h u b}_{t}
\end{aligned}
$$

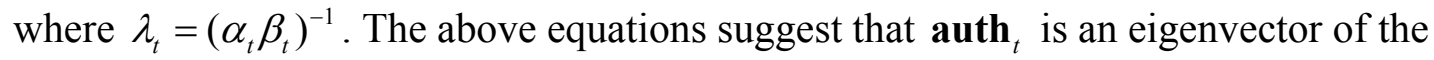
matrix $A_{t}^{* T} A_{t}^{*}$, and $\mathbf{h u b}$ is an eigenvector of $A_{t}^{*} A_{t}^{* T}$. We use the eigenvectors

\footnotetext{
${ }^{13}$ In addition to highlighting the role of dependence in the network, authority and hub score avoid the problem of applying Katz-Bonacich centrality to the share network. The column-stochastic property of the adjacency matrix, together with the restriction on the maximum path length from core to periphery, renders the calculation of Katz-Bonacich centrality trivial.

${ }^{14}$ The node HHI introduced as a basic structural indicator also measures interdependence and diversification. Intuitively, consider authority/hub measure in the share network as a weighted HHI measure that puts more weight on important counterparts. The recursive nature of this pair of measures thus allows us to determine exact evolution of interdependence among high/low-importance country groups.
} 
corresponding to the dominant eigenvalue $\lambda_{1}^{*}$ for both matrices to calculate the authority and hub measure.

Literature sees limited use of authority and hub measures in analyzing financial networks. León and Pérez (2013) recognize the clearly defined role of the Colombian financial market infrastructures and discuss the advantage of authority and hub measure in capturing central nodes. Alvers et al (2013), Chinazzi et al (2013) and León, Pérez, and Renneboog (2013) use authority and hub measure as a supplement to traditional centrality measures to analyze global financial network, European interbank market and Colombia sovereign securities market, respectively.

\section{Understanding Cross-Border Banking Linkages: Results from Network Analysis}

\section{Structural Characteristics}

We start with a simple visualization exercise that illustrates the evolution of our network. Figure 3 plots three snapshots of the network using a force-based algorithm. The algorithm clearly illustrates the unbalanced nature of the network, with a small number of reporting and non-reporting countries accounting for most of the connections. The crisis period is characterized by a lower number and weaker strength of connections, whereas recent periods have seen a modest recovery of connectedness within the network. A remarkable feature of the 2016Q2 network is the weaker interconnectedness of European countries compared to the 2006Q1 counterpart. The force-based algorithm of Jacomy et al. (2014) pushes a number of European lenders, such as Italy (ITA) and Portugal (PRT), farther from the center of the network.

Visualizations of the entire banking network provide a heuristic characterization, but omit quantitative details of the network's evolution. Now, we proceed to characterize the overall property of the network using network statistics. Figure 4 plots the evolution of basic structural indicators - degree, strength and concentration. The crisis brings about large perturbation in these indicators. From the lender perspective, average out-degree and outstrength experience a sharp drop during crisis period. Less is sent out by lenders after the crisis, and the downward trend has not yet reversed. The average number of outbound linkages of lenders has slightly picked up since the crisis, but has not yet reached pre-crisis level. Concentration reaches its peak around crisis time, and has been relatively stable since 2012. Further breakdown of average node degree and strength suggests that the overall dynamics of basic indicators are primarily driven by major global lenders and European lenders, but that the non-traditional lenders do not experience a significant fall in either outdegree or out-strength (Figure 5). These basic indicators suggest a recovery of the network to a limited extent in the aftermath of the crisis with core global and European lenders driving the reduction in the number and size of financial linkages.

From a borrower's perspective, while the average in-degree of the network in 2016Q2 is lower than the pre-crisis level, the difference is not as pronounced as in-strength. As the network is unbalanced, we further investigate its global structural evolution through in- 
degree distribution, which might be highly skewed. Figure 6 displays the in-degree distributions for three snapshots of the network. Compared to the distribution immediately before the crisis (2007Q4), the distribution in 2016Q2 for reporting countries exhibits a strong leftward shift, suggesting an overall decline in lending connections within the reporting countries. Kolmogorov-Smirnov test rejects the null hypothesis of same distribution at $1 \%$ level, suggesting an overall decline in lending connections within the reporting countries. However, for all countries and for non-reporting countries only, the indegree distributions have a shorter tail and become less skewed when we compare them with their pre-crisis counterparts. ${ }^{15}$ This simple comparison of distributions suggest that the

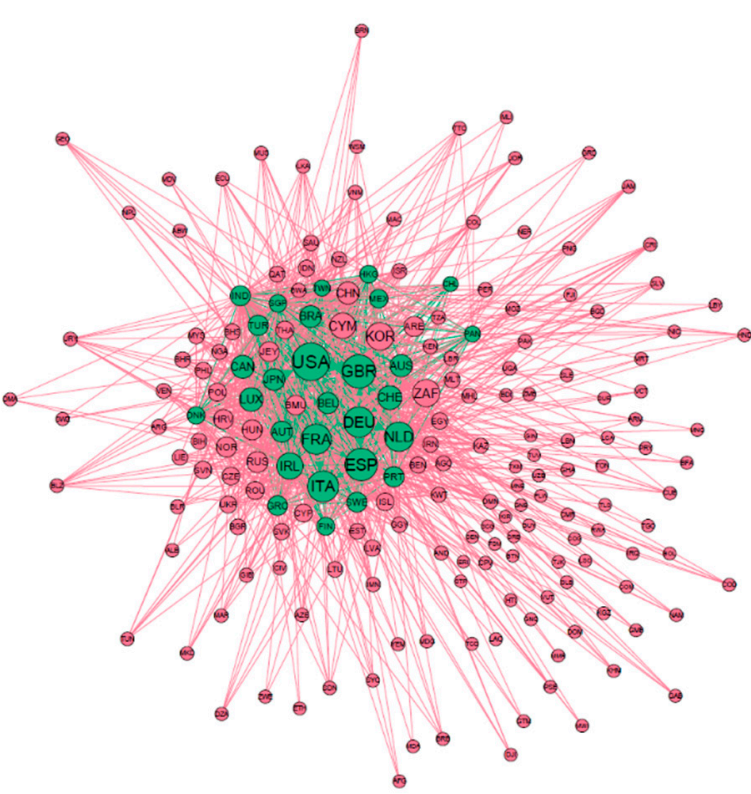

(a) Pre-Crisis (2006Q1)

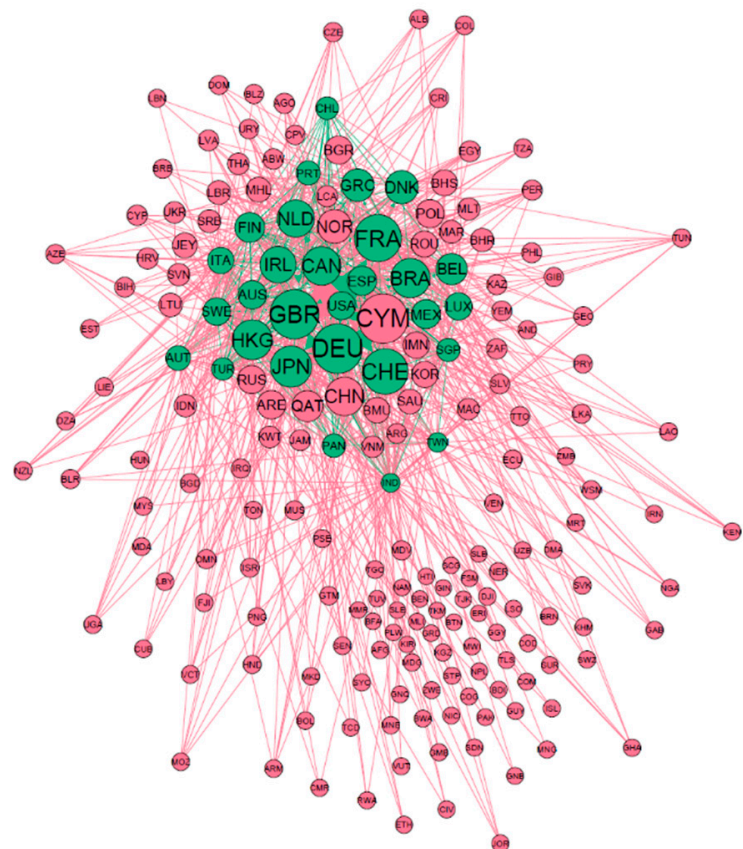

(b) During the Crisis (2009Q1)

\footnotetext{
${ }^{15}$ Kolmogorov-Smirnov tests comparing 2016Q2 distribution to both 2006Q1 and 2007Q4 unanimously reject the null hypothesis at $10 \%$ level, for both the all countries sample and the non-reporting countries sample.
} 


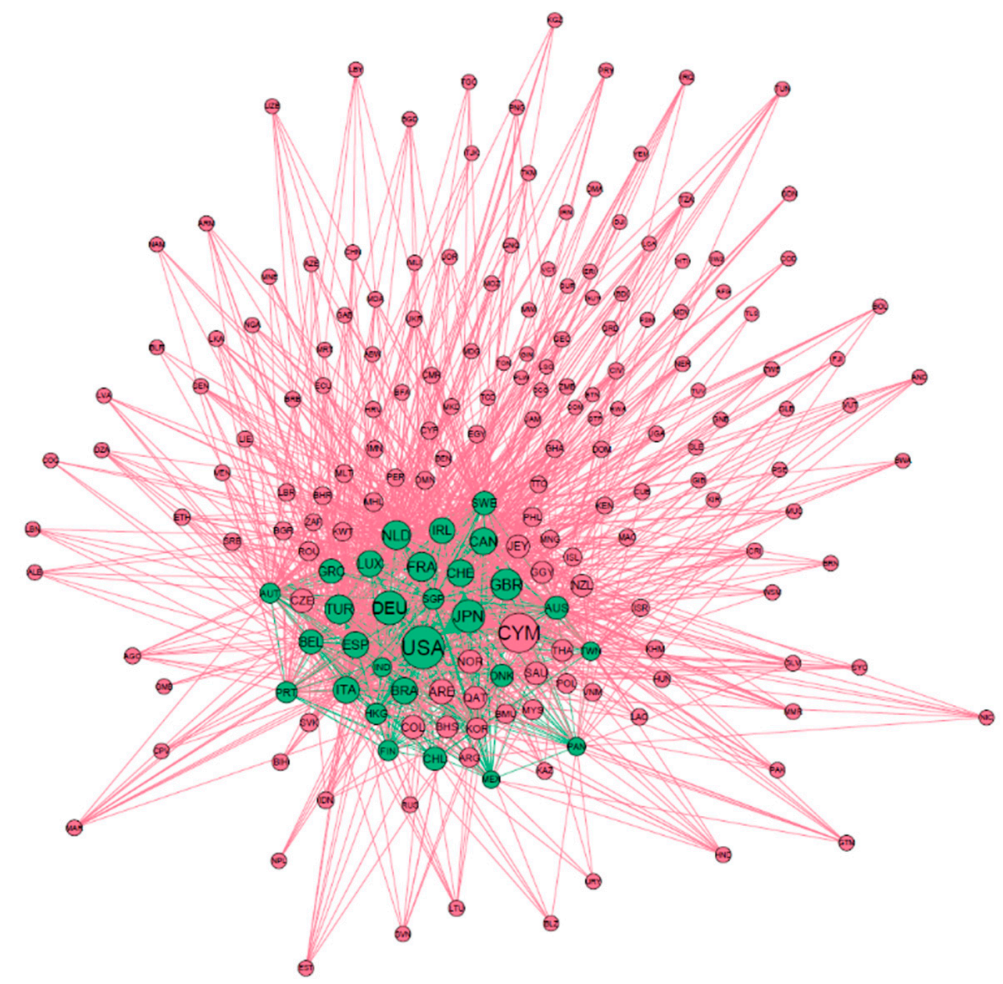

(c) Recent (2016Q2)

Figure 3. Network Visualization

Note: Figure 3 uses force-based algorithm (Jacomy et al., 2014) to visualize the global banking network with a core-peripheral structure. Green nodes denote reporting countries, with the links between reporting countries colored green. Node size is based on Katz-Bonacich centrality. 


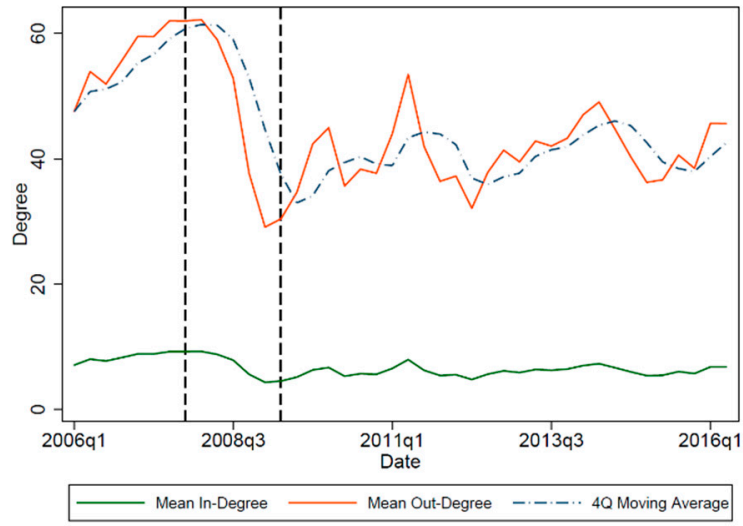

(a) Degree

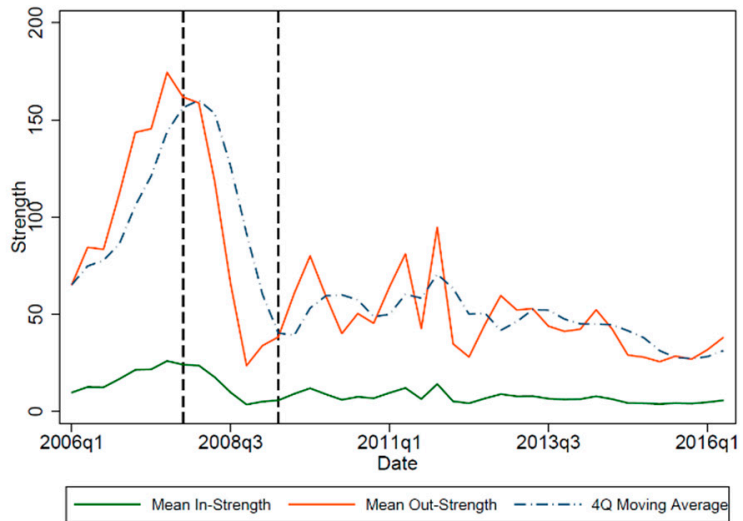

(b) Strength

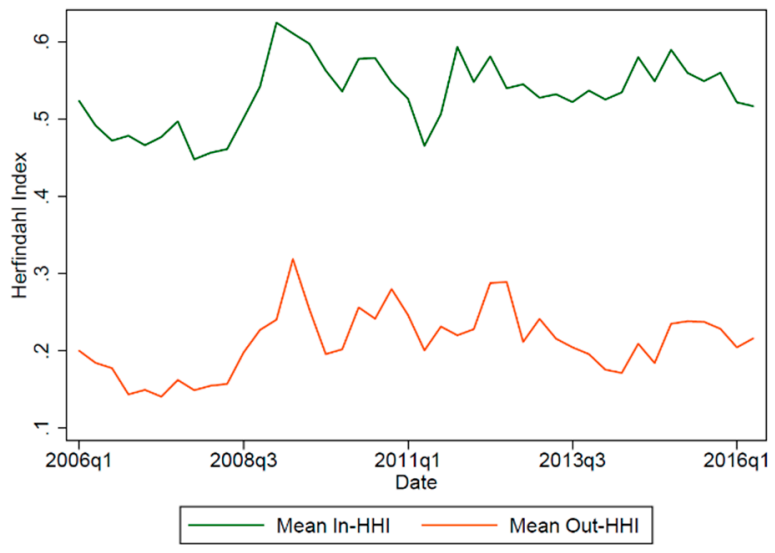

(c) HHI

Figure 4. Evolution of Degree, Strength and Concentration

Note: Figure 4 plots basic indicators of the global banking network. The definition of degree, strength and concentration in a directed, weighted network follows Section 2.2.

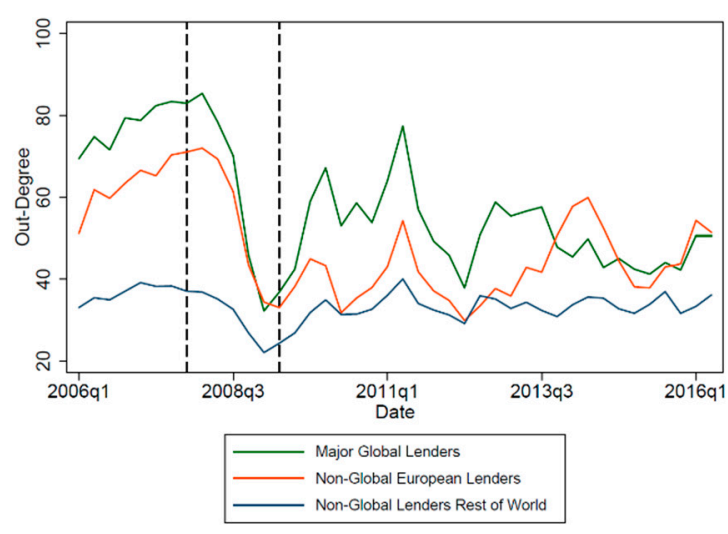

(a) Out-Degree

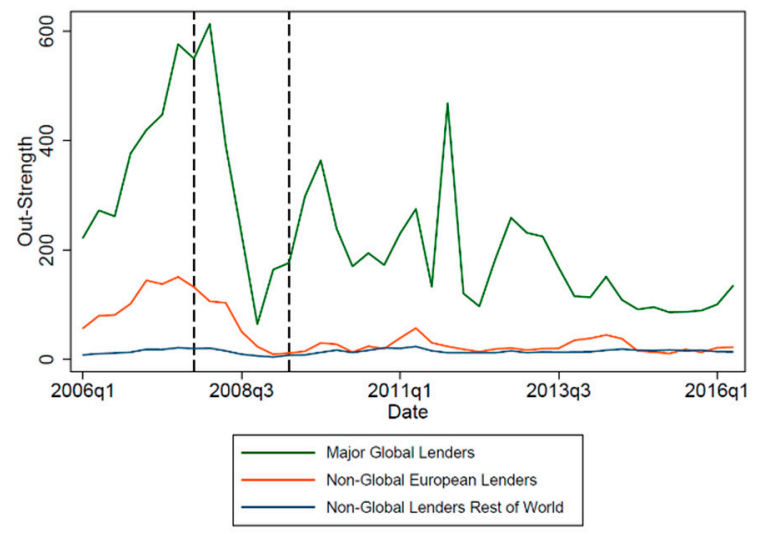

(b) Out-Strength

Figure 5. Network Statistics by Lender Groups

Note: Figure 5 breaks down basic network indicators to three distinct lender groups. The classification of lenders follows Table 1. The definition of degree, strength in a directed, weighted network follows Section 2.2. 


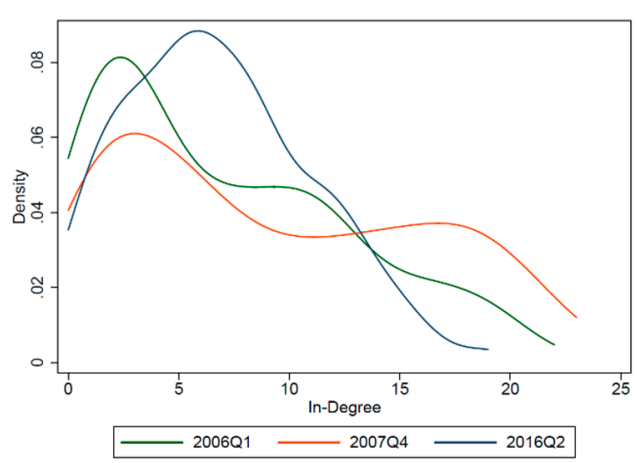

(a) All Countries

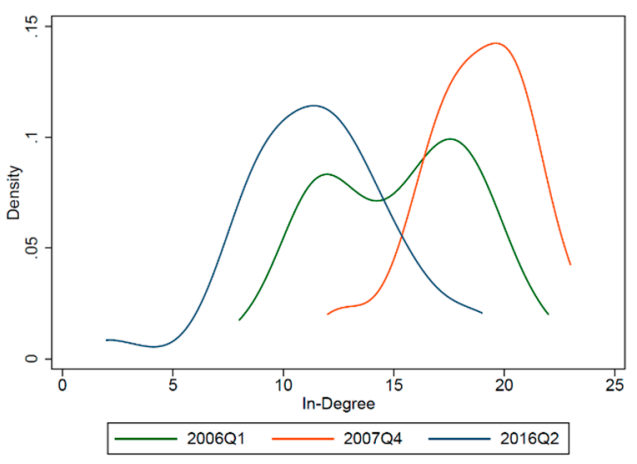

(b) Reporting Countries Only

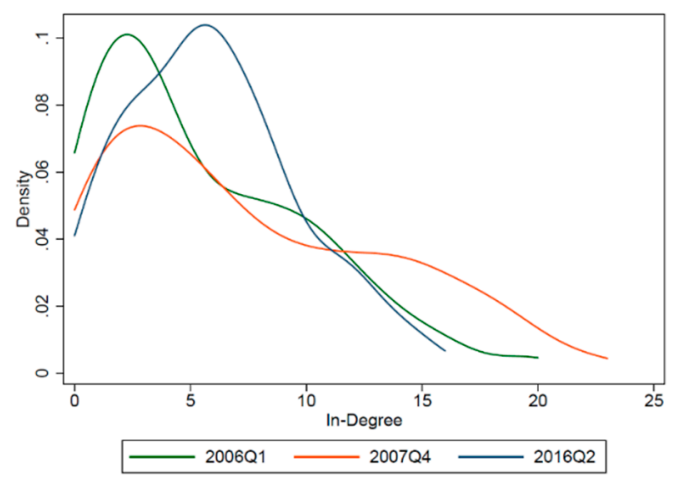

(c) Non-Reporting Countries Only

\section{Figure 6. In-Degree Distribution}

Note: Figure 6 plots the in-degree distribution for the first quarter, immediately before crisis, and the last quarter of the global banking networks in our sample. The density is estimated using a Gaussian kernel.

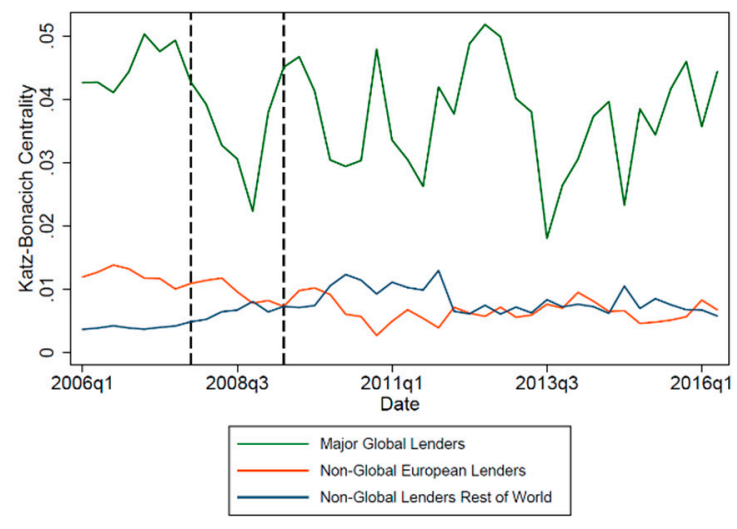

(a) Reporting Countries

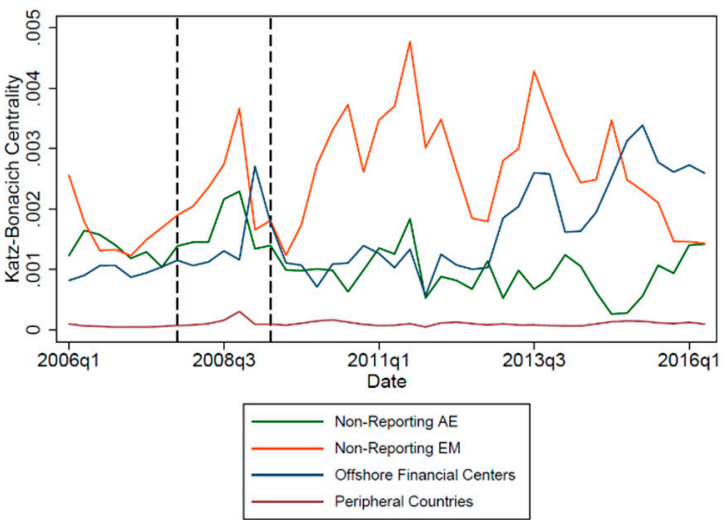

(b) Non-Reporting Countries

Figure 7. Mean Katz-Bonacich Centrality by Country Groups

Note: Figure 7 plots the evolution of mean Katz-Bonacich centrality for each group of countries identified in the network. The classification of lenders follows Table 1. Offshore financial centers, non-reporting AEs and EMs are defined following IMF definition. Peripheral countries refer to all countries not included in other categories. The definition of Katz-Bonacich centrality in a directed, weighted network follows Section 2.2. 
underlying dynamics of cross-border lending connections cannot be fully reflected in average statistics - recent networks have sparser connections in the core, which help drive down the mean statistics, but a number of non-reporting countries have been expanding their borrowing relationship to new lenders since the crisis.

\section{Evolution of Node-Level Importance}

Results in the previous section indicate the presence of substantial heterogeneity in the underlying dynamics for different groups of countries. By using node-level importance measure, we are able to determine if the decreasing overall volume masks the underlying shift in the structural importance of each group and each country to the network.

Figure 7 plots the evolution of average Katz-Bonacich centrality for reporting and nonreporting groups and confirms the validity of this measure for characterizing countries' importance in the network. Unsurprisingly, major global lenders have significantly higher Katz-Bonacich centrality values than the other two non-major global lender groups (Figure 7a). Albeit with large volatility, the evolution of average centrality suggests that traditional large lenders' status as global financial centers have not changed much, despite a drop in the amount of their lending. What's more interesting to note is the persistent decline of nonglobal European lenders' importance in the network and the steady rise of lenders from other regions. From 2010Q2, the former group's importance has been surpassed by the latter group, whose centrality is not affected by the crisis, and the difference is more pronounced during the Eurozone debt crisis. On the borrowers' side (Figure 7b), average Katz-Bonacich centrality for non-reporting emerging market economies outgrow their AE counterparts, mostly European economies. The latter's average Katz-Bonacich centrality experienced a steady decline after the crisis, but has picked up recently.

Figure 8 plots the 4-quarter average of average authority measure for non-reporting and hub measure for reporting countries. A flat hub measure implies the relative stability of lenders' role in the network, with major global lenders serving as large financial hubs and connecting to borrowers with large authority measures. On the other hand, we witness a clear downward trend of authority score for both offshore financial centers and major non-reporting borrowers (AEs and EMs). The recursive nature of authority measure offers a clear interpretation, that these borrowers have reduced their dependence on major global lenders with high hub measure and have resorted to new funding sources with lower hub scores. Figure 8(c) plots the yearly evolution of authority and in-HHI measures for non-reporting emerging market economies. The sharp drop of authority score starting from the 2011 peak is not accompanied by a significant movement in concentration, measured by in-HHI. The decline in authority score, as a result, mainly reflects EM borrowers' reshuffle of their banking partners. Combined with the evidence of a rising importance of non-European regional lenders, exercises on authority and hub score provide an early hint of the possible regionalization of the network.

Our node-level importance measures provide a solid ground for us to identify individual countries as key players in the network. We construct ranks based on annual average of the Katz-Bonacich and authority/hub measures and plot the heatmaps of the ranks. Katz- 
Bonacich and the authority/hub score offer two distinct ways of characterizing the role of individual country in the global banking network. The authority/hub score, defined on the share network, focuses on the dependent relationship between the lender-borrower pair, so that borrowers with a high authority score can be characterized as poorly diversified countries connected to important lenders defined by their hub score. The Katz-Bonacich measure, on the other hand, is defined on the normalized baseline network (represented by the adjacency matrix $\hat{A}_{t}$, defined above) and captures the notion of interconnectedness on the role of each player in the network. This measure represents how well interconnected a player is to other important players, either directly or indirectly. ${ }^{16}$

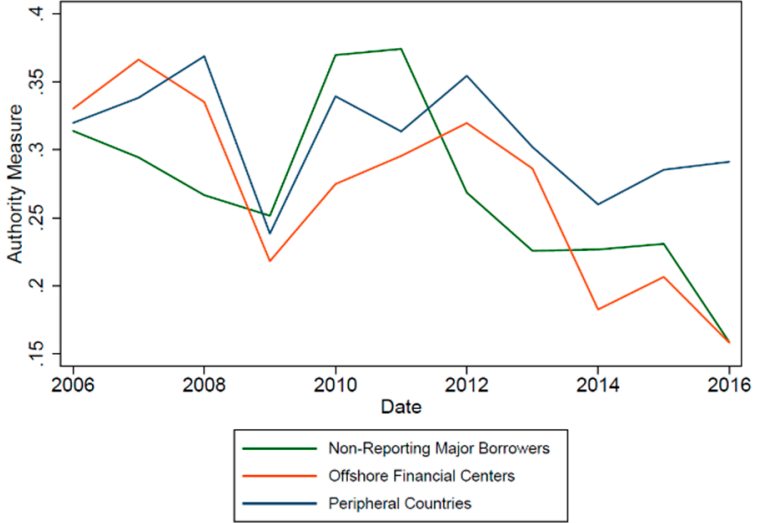

(a) Authority Measure (Non-Reporting)

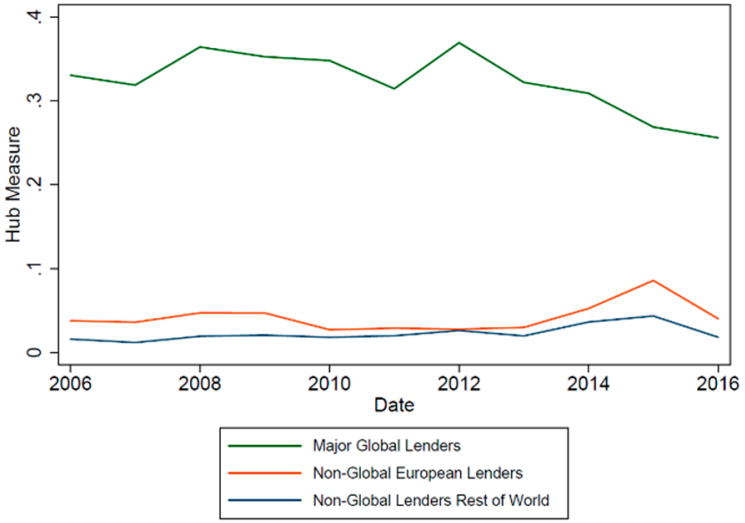

(b) Hub Measure (Reporting)

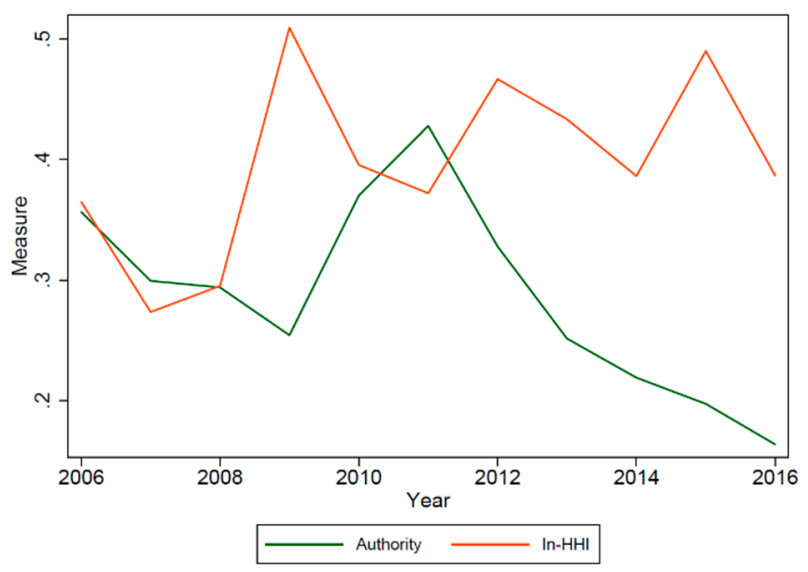

(c) Authority and In-HHI (Non-Reporting EMs)

\section{Figure 8. Mean Authority/Hub Measure by Country Groups}

Note: Figure 8 plots the mean authority/hub measure for each country group. The measures are aggregated into yearly series by taking $4 \mathrm{Q}$ average. The definition of authority and hub measure in a directed, weighted network follows Section 2.2. Country classification follows Table 1. Non-reporting major borrowers including nonreporting AEs and EMs.

${ }^{16}$ Indeed, in our data, we find that these two measures reveal different aspects of importance in the global banking network: restricted to all countries with top-five centrality authority score or Katz-Bonacich centrality during the sample period, the rank correlation is 0.1577 , implying only modest-to-weak co-movement. 


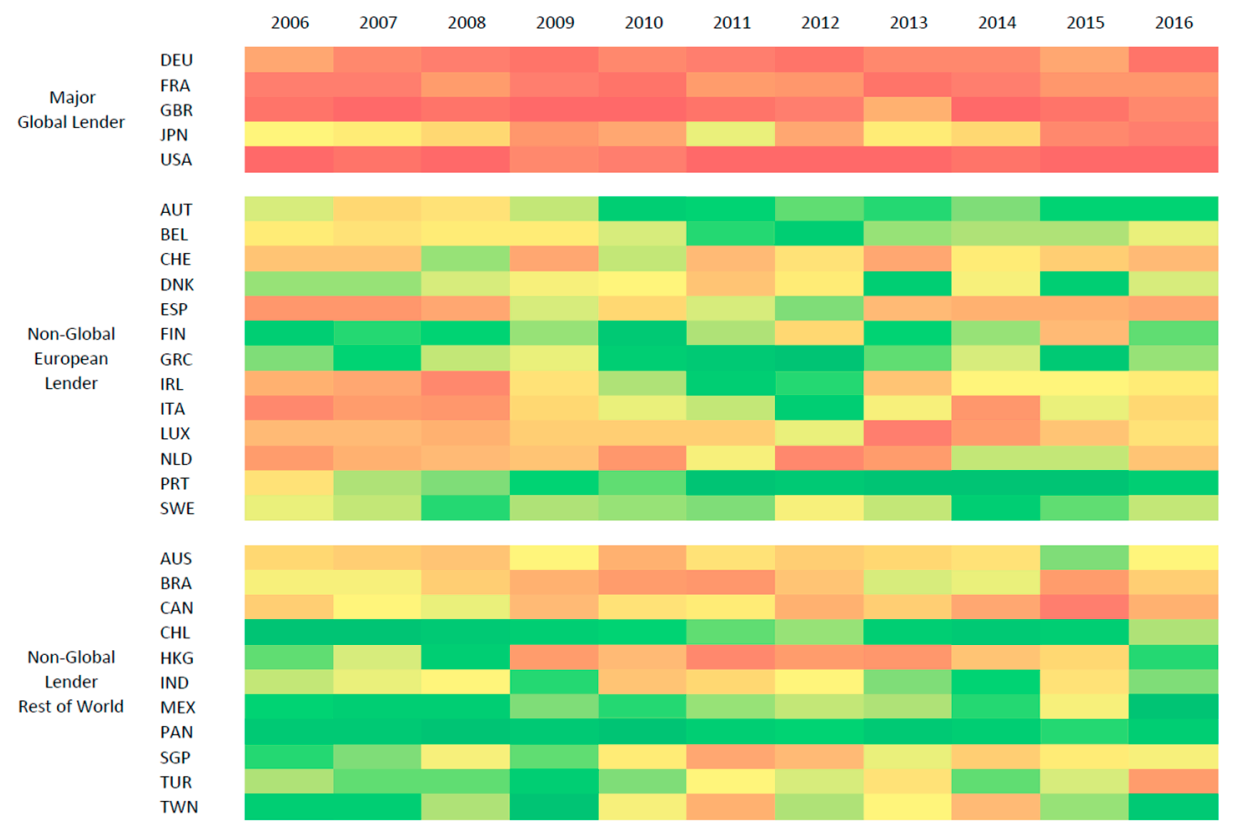

(a) Katz-Bonacich Centrality Rank

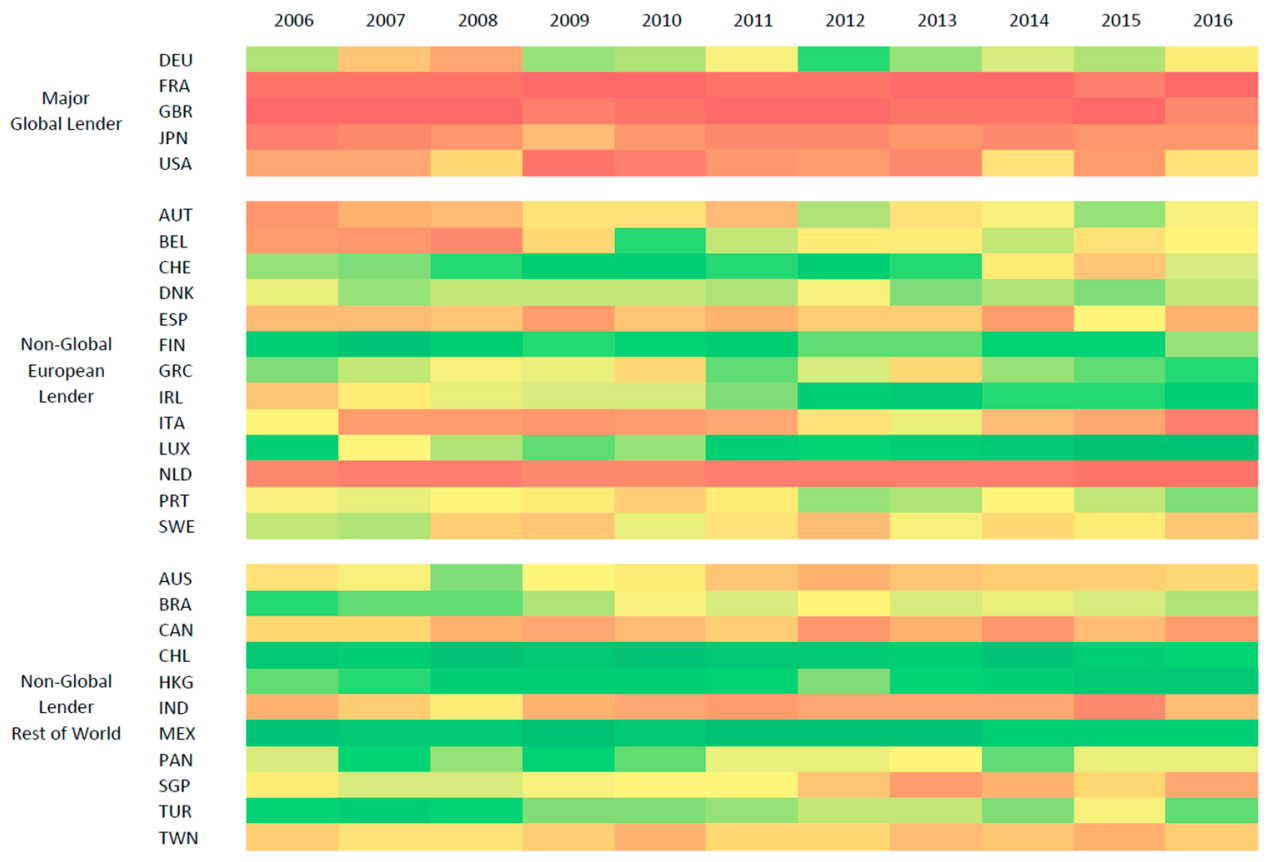

(b) Hub Measure Rank

\section{Figure 9. Heatmap: Lender Rank Distribution}

Note: Figure 9 plots the heatmaps showing the rank distribution of lender node importance measure, at annual frequency. A low rank corresponds to high importance measures and a red color. A high rank corresponds to low importance and a blue color. 
In this context, Figure 9 focuses on the entire lender profile. The crisis clearly has promoted some mobility across the lender distribution. Figure 9a suggests that Asia-Pacific and Latin America are two regions in which borrowers start actively seeking alternative sources of funding from 2010 onwards, resulting in a moderate rise of importance for Australia, Brazil, Hong Kong and Singapore, and the decline of secondary European lenders such as Ireland, Belgium, Italy and Austria. ${ }^{17}$ The role of major global lenders is hardly affected by the crisis in terms of their Katz-Bonacich centrality ranking. Performing the rank of lender using their Hub measure, produce similar dynamics (see Figure 9b) despite highlighting some differences. Asian lenders seem to increase in their relative ranking, highlighting that they lend relatively more to poorly diversified countries (with high authority scores) connected to important lenders. On the opposite side, Germany seems to follow a different lending pattern, displaying a low ranking in Figure $9 \mathrm{~b}$ and indicating that it does not specialize as much in lending to poorly diversified countries.

We also identify regional key borrower players by choosing countries with large KatzBonacich or authority measure. Figure 10a plots their rank in the entire network using the former measure. Top nodes for each region seem to enjoy a stable ranking within the entire system before the crisis. However, some traditional European top lender-borrowers, such as Spain and Italy, saw their ranks in the global banking network drop during and after the crisis. Measured by Katz-Bonacich centrality and echoing the lender profile of Figure 9, the role of top Asian countries as lender-borrowers, including Hong Kong, Singapore, India and the non-reporting China, is further elevated after the crisis. The Katz-Bonacich measure is also able to capture the abrupt drop in the rank of China in 2016, during which the country faces large financial outflows amid stricter regulations and gloom economic prospect.

Consistent with the overall declining trend in authority scores, top regional players with high authority scores from less-connected regions such as Africa and Asia have decreased their dependence on large financial hubs after the crisis, especially during the European crisis (see Figure 10b). The exercises also identify a number of important offshore financial centers in Europe as key borrowers, including Guernsey, Jersey and Isle of Man, whose status as British Crown dependencies earns for them sustained and heavily dependent connections with important hubs such as the United Kingdom.

\section{Lending through affiliates vs direct cross-border lending}

Several analyses in the literature have also highlighted an increase in the regionalization of international banks through changes in the nationality of foreign affiliates. The crisis triggered the reorganization of many international bank groups, which included both their selling of foreign affiliates (Claessens and van Horen 2015) or changes in their funding model (e.g., increase in domestic deposit funding in Eastern Europe as highlighted by Impavido, Rudolph, and Ruggerone 2013). The way that we have mapped the global financial network provides us an aggregate look at these trends. Figure 11 plots the average

\footnotetext{
${ }^{17}$ This trend of increasing importance of Asian lenders seems to have decreased at the end of the sample, when banking inflows to China have reversed (negative inflows)
} 


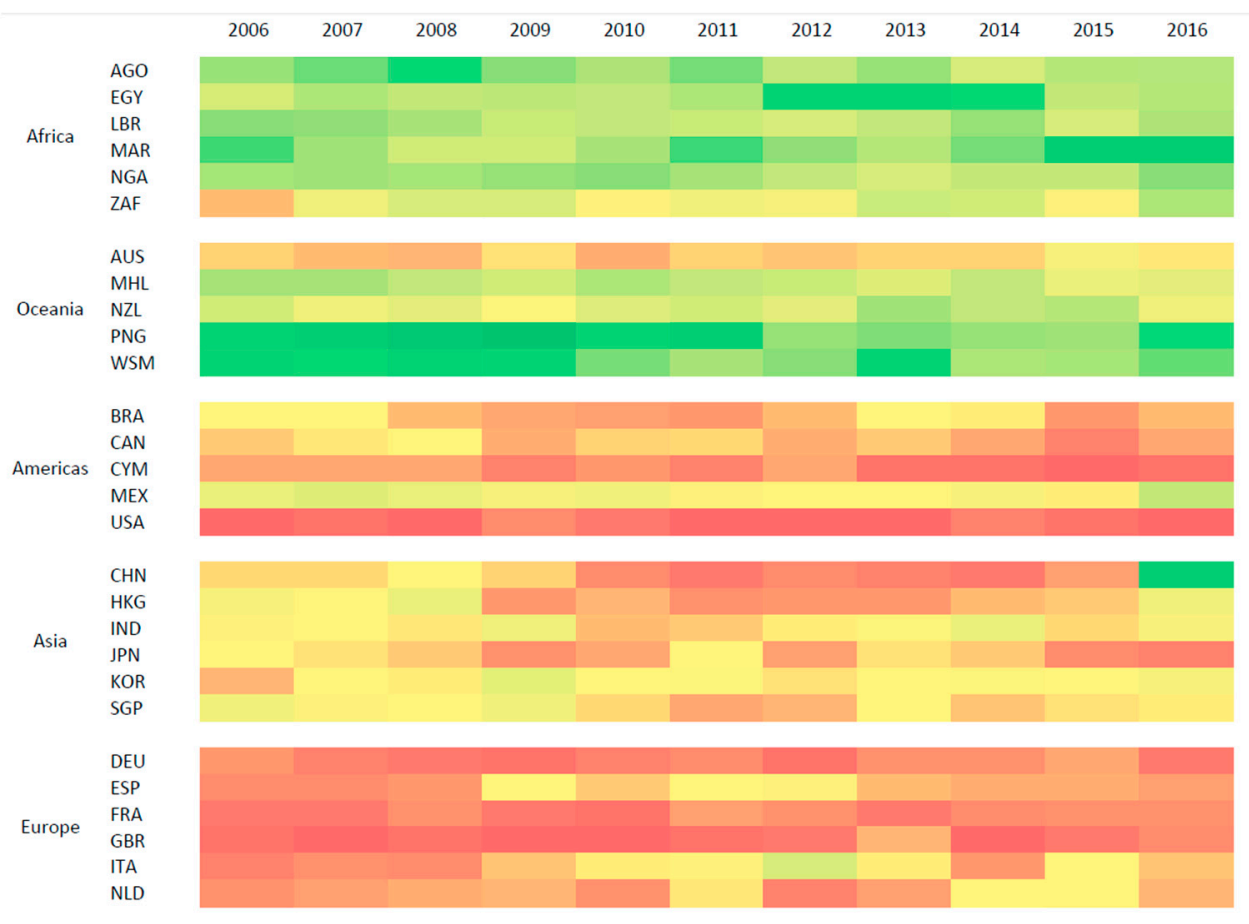

(a) Katz-Bonacich Centrality Rank

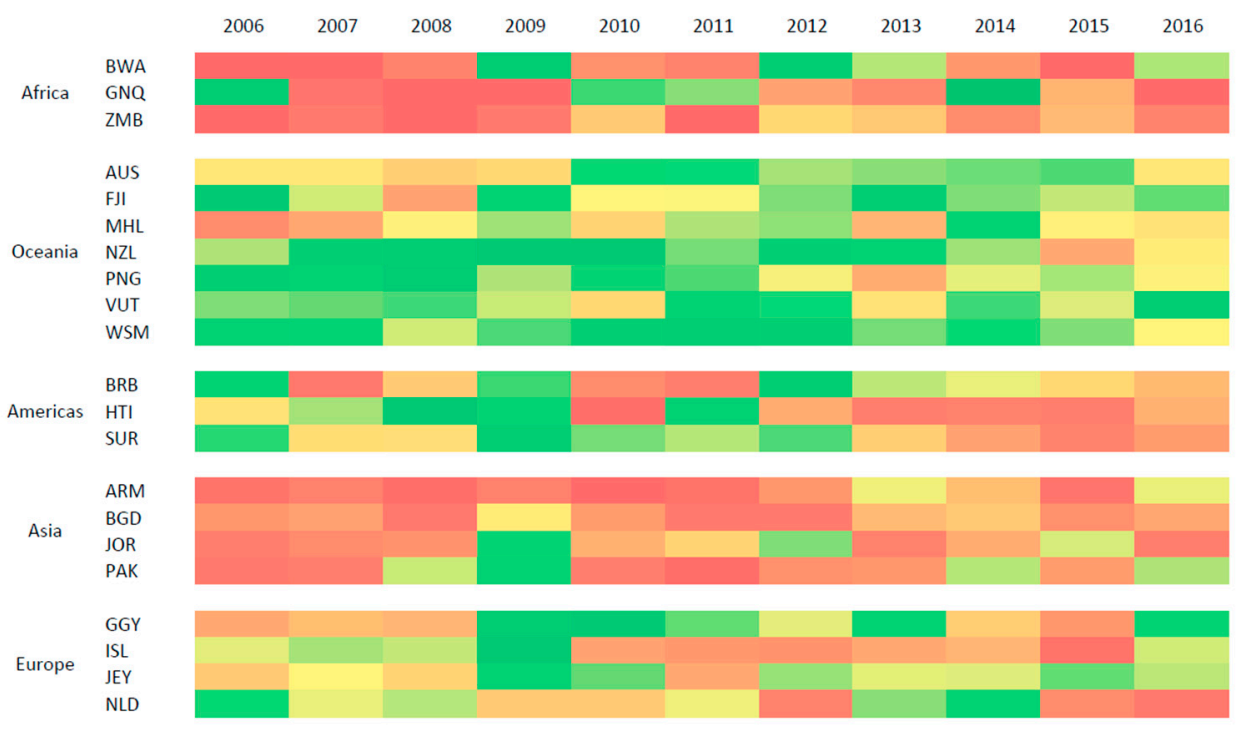

(b) Authority Measure Rank

\section{Figure 10. Heatmap: Regional Key Players Rank Distribution}

Note: Figure 10 plots the heatmaps showing the rank distribution of node importance measures for important regional country players, at annual frequency. Countries appearing in the plots (identified as important countries), must rank as one of the top five countries in its region, using the corresponding measure, for three years during the sample period (not necessarily consecutive). Their overall rank in the entire network is used to color the cell. A low rank corresponds to high importance measures and a red color. A high rank corresponds to low importance and a green color. 
out-degree and out-strength by groups of lenders regarding their adjusted local claims. A clear downward trend on both the out-degree and the out-strength for non-global European lenders is observed, while both measures for non-global lenders out of Europe is steadily picking up relative to the levels immediately after crisis. Since within-region flows account for most of the local claims flow in Asia-Pacific and Latin-America, Figure 11 suggests, from an aggregate level, that global banks' operations through local affiliates in these areas have subsided and given way to a more regionalized lending structure. This pattern is possible even though domestic funding has increased. Figure 12 plots the distribution of deposit-loan ratio for three selected quarters, weighted by local claims as reported by CBS data. For all groups of lenders, the distribution seems to assign more mass to the right in recent period, yet this switch to reliance on local deposit funding is most remarkable for affiliates of major global lenders and non-global European lenders, located in European and the Western Hemisphere. Indeed, Kolmogorov-Smirnov tests comparing 2016Q2 distribution to 2006Q1 and 2007Q4 distributions reject the null hypothesis at 1\% level for major global lenders and non-global European lenders, but fails to reject the null hypothesis at $10 \%$ level for the group of other lenders.

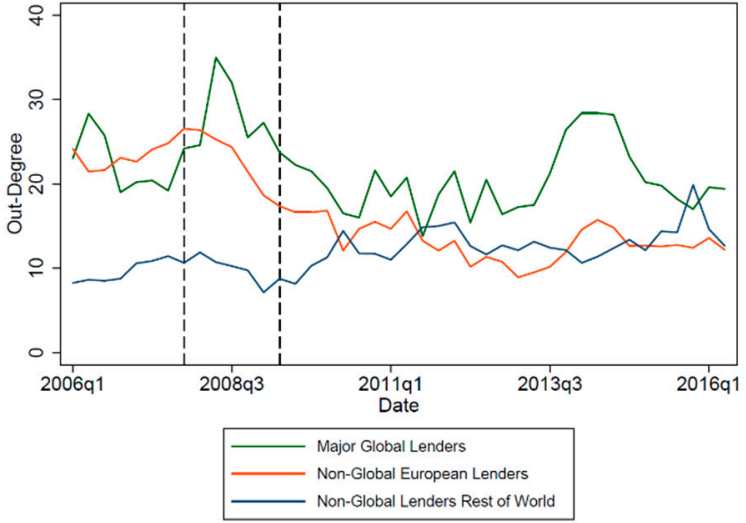

(a) Out-Degree

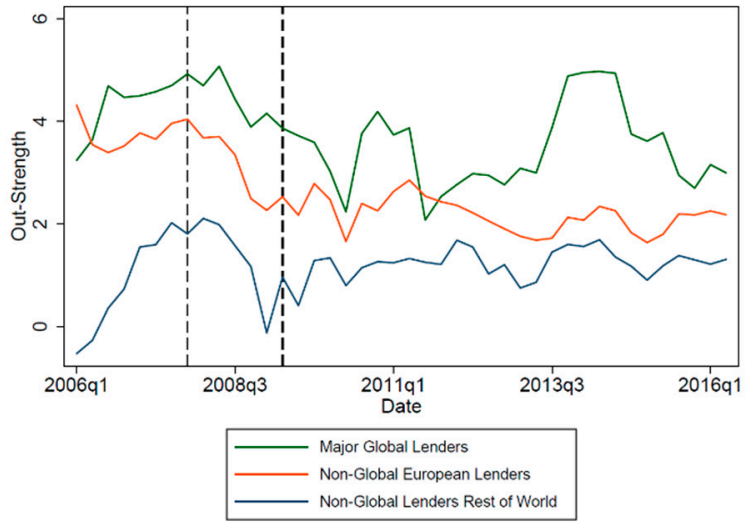

(b) Out-Strength

\section{Figure 11. Evolution of Average Out-Degree and Out-Strength by Lender Tier - Adjusted Local Claims of Affiliates}

Note: Average Out-Strength is log-transformed to facilitate visual comparison. Adjusted local claims refer to local claims scaled down by deposit-loan ratio using the methodology of Cerutti (2015). 


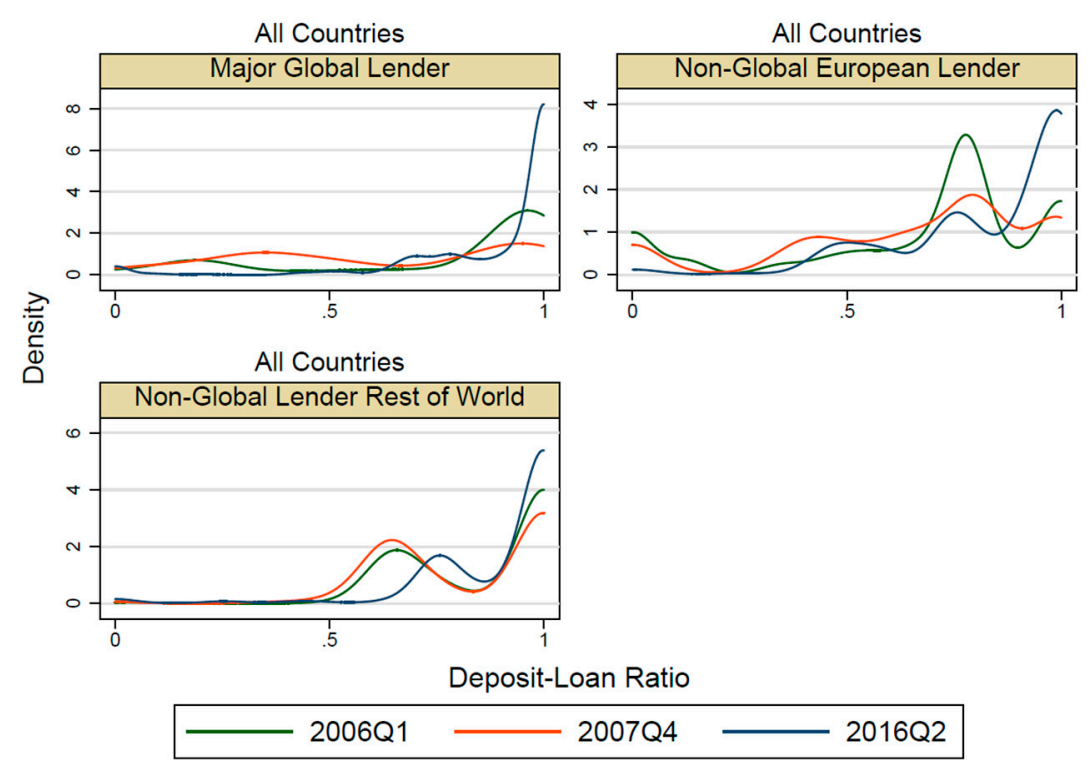

(a) By Lender Group

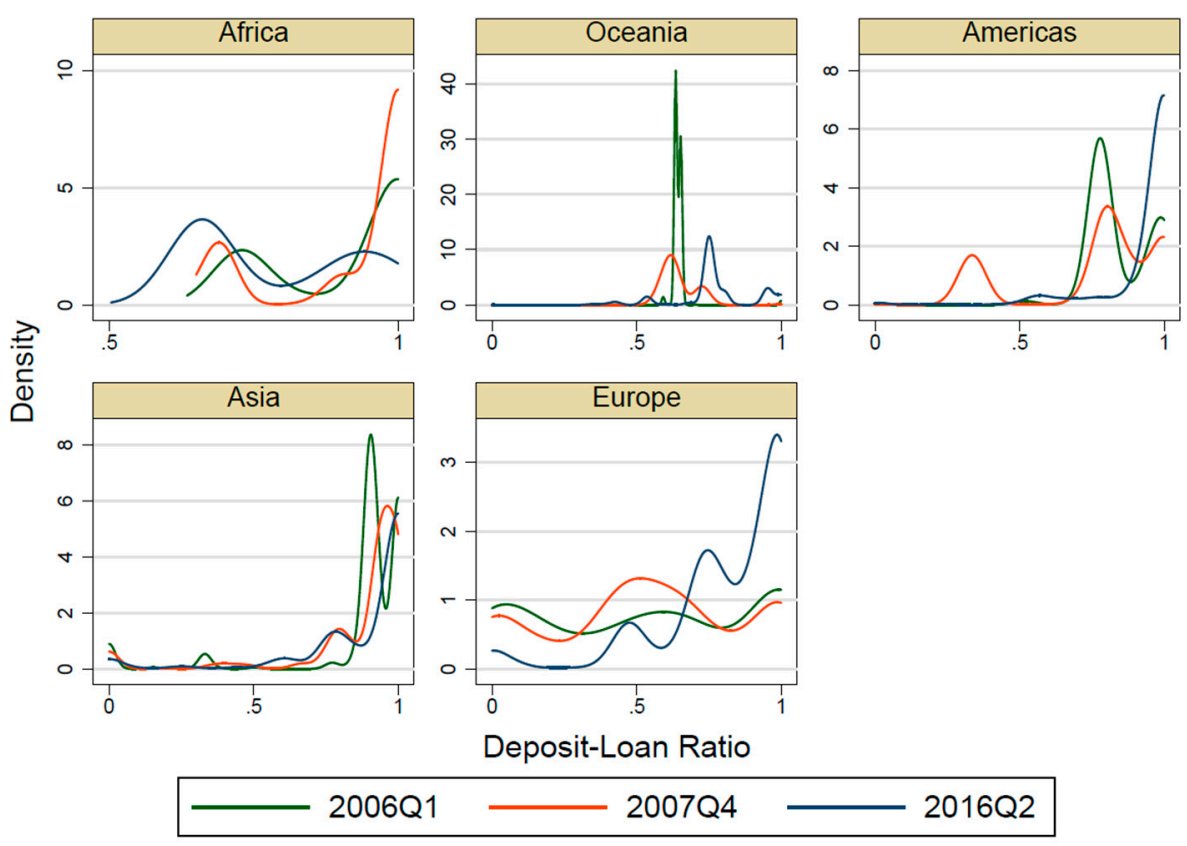

(b) By Borrower Region

\section{Figure 12. Deposit-Loan Ratio: Cross-Sectional Distribution}

Note: Figure 12 plots three snapshots of the kernel density estimation of deposit-loan ratio weighted by unadjusted local claims reported in CBS dataset, for lender-borrower pairs with positive local claim exposures. The density is estimated using a Gaussian kernel. Deposit-loan ratio data for each country is aggregated from BankScope Database. 

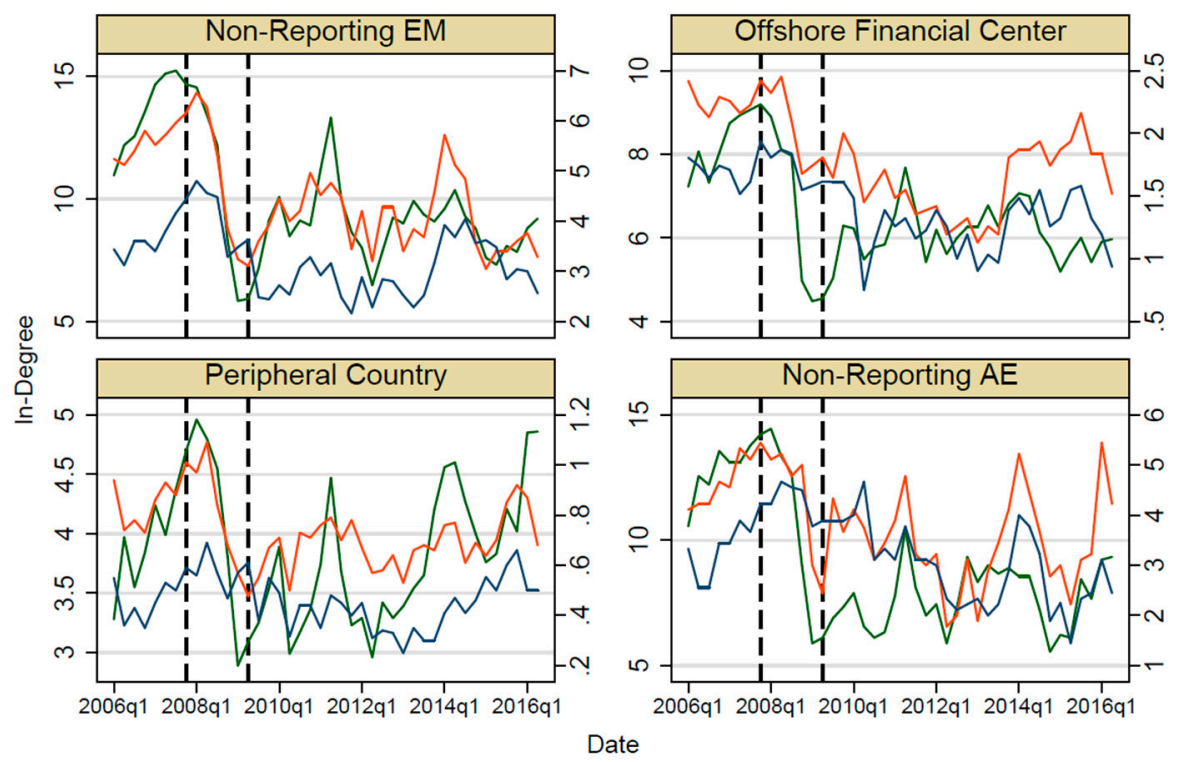

Cross-Border

Local (Right Axis)

Adjusted Local (Right Axis)

(a) Non-Reporting Countries: Average In-Degree by Group and Type of Claims
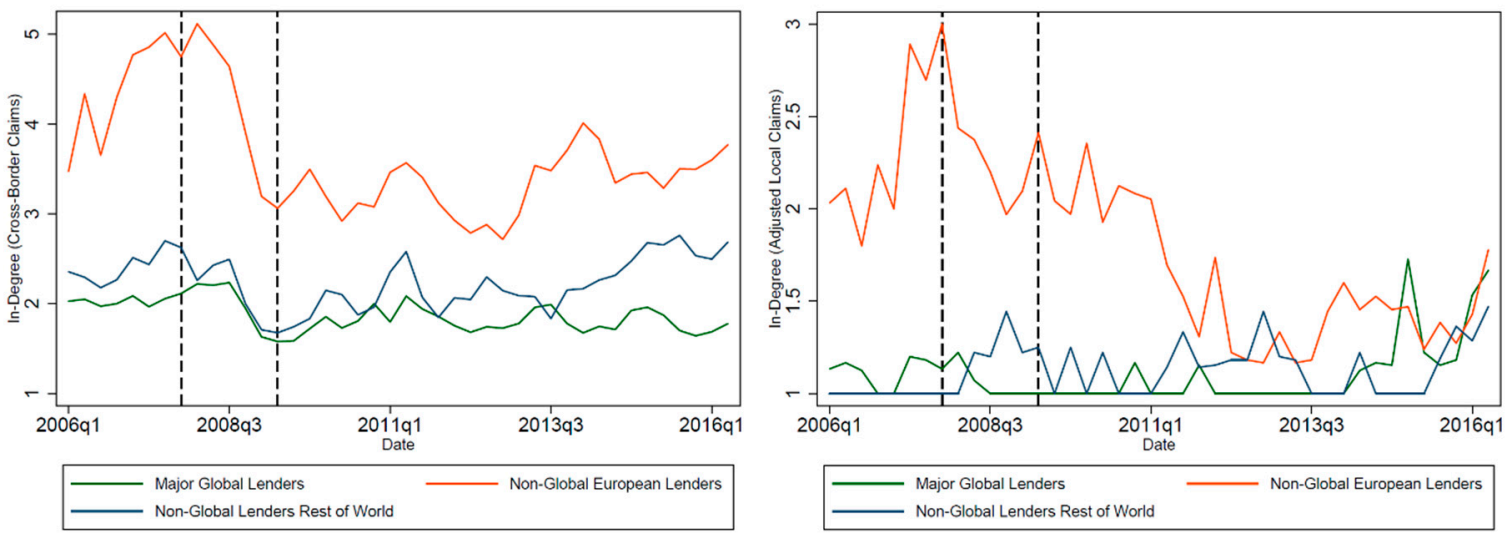

(b) Cross-Border

Peripheral Countries: Claims by Type of Lenders

(c) Adjusted Local

Figure 13. In-Degree by Types of Borrower and Country Group

Note: Peripheral Countries include all non-reporting countries except advanced economies, emerging market economies and offshore financial centers. 
On the borrowers' side, Figure 13a plots the average in-degree of cross-border and local claims by type of borrowers. Among all groups of borrowers, peripheral countries (all nonreporting countries except $\mathrm{AE}, \mathrm{EM}$ and offshore financial centers) stand out as the only group of borrowers that maintain the level of local claim linkages compared to that immediately before the crisis. Figure 13b inspects the sources of these local claim linkages, and find remarkable retrenchment of affiliates from non-global European lenders. This loss of links is partially compensated by an increasing presence of non-global, non-European lenders. Figure 14 considers individual lenders' relative positions in the network, and plots a set of heatmaps, similar to Figure 9, on the rank of Katz-Bonacich centrality of lenders with nonzero claim components in the sample. After the crisis, emerging market lenders rise along the ranks in both components of international banking flows. While the overall trend is driven primarily by cross-border claims (see Figure 14b), which account for the majority of flows, emerging market lenders see their importance boosted even higher in the network of local claims (See Figure 14a). This is especially the case of Australian, Brazilian and Canadian banks, which have boosted their cross-border lending. Nonetheless, major global banks have retained their leading roles in terms of direct cross-border claims, which retains the highest scores throughout the period. This is not the case on adjusted local claims, where US and Canada seem to have changed their lending strategy away of foreign affiliates. ${ }^{18}$ Figure 14 also show some heterogeneity across non-global European banks. Despite the impact of the European crisis in their parent bank country, Spanish and Italian banks display relatively high scores in both adjusted local claims and direct cross-border lending at the end of the sample.

\section{Towards a Regionalization Process?}

Previous results, including borrowers' decreasing dependence on core lenders as well as the rise in status for lenders outside Europe provide hints about the regionalization of some parts of the global banking network. The increase in the regionalization of adjusted local claims also offers illustrative evidence for the regionalization argument. To provide more deterministic support, we propose a novel method for measuring the level of regionalization using network theory, as well as regression analysis of cross-border lending.

\section{Further network evidence: A Modularity Analysis}

The concept of regionalization is closely connected to the existence of community structure in the network. A community is characterized by a cluster of nodes with dense connections, but weak out-of-group connection. A number of methods have been developed to detect community structures in networks, of which the most popular family of methods is based on optimizing an objective function, known as modularity (Newman and Girvan, 2004).

Intuitively, given a division of the network into community structures, the concept of modularity measures the strength of the division by the difference between the

\footnotetext{
${ }^{18}$ Citibank, which was the bank with the broadest geographical network of affiliates (see Cerutti et al 2007) before the crisis, restructured and sold in 2016 its Argentinean affiliate, which has been operating since 1914 and it was Citibank first non-U.S. branch.
} 


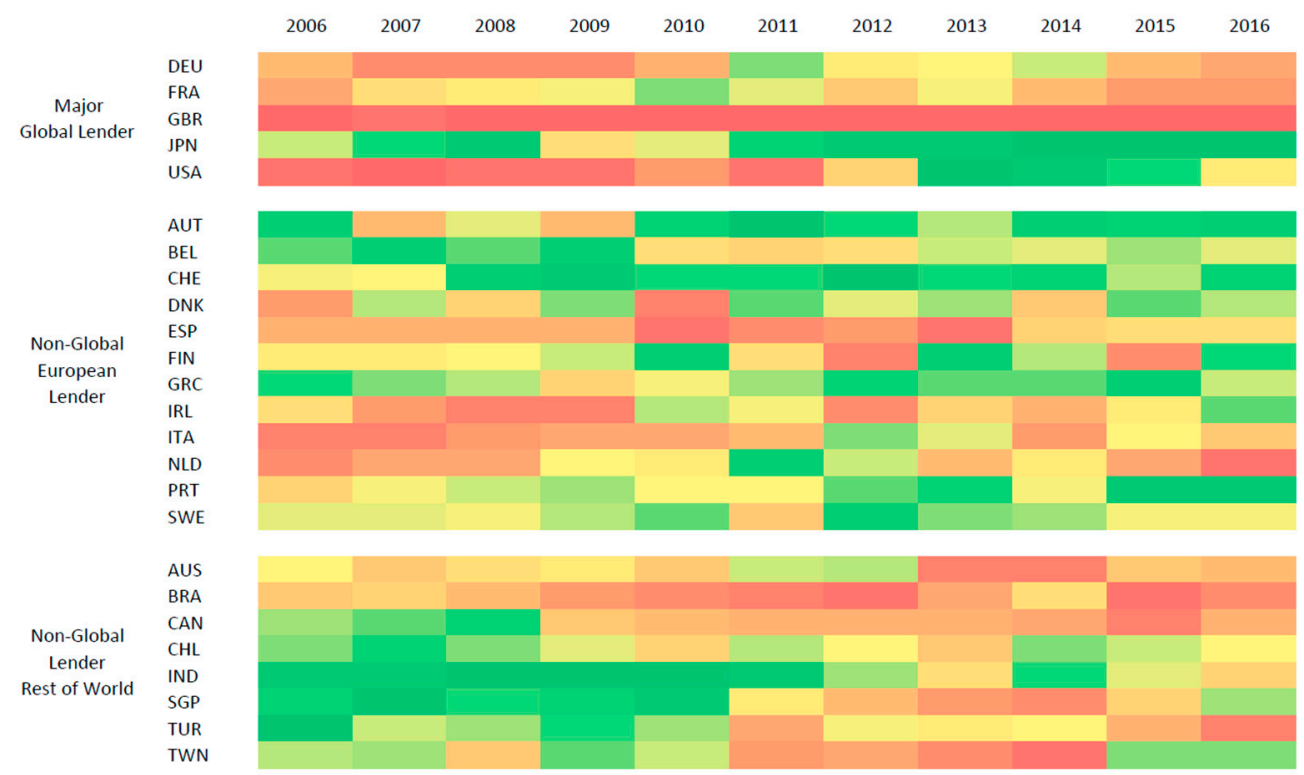

(a) Adjusted Local Claims

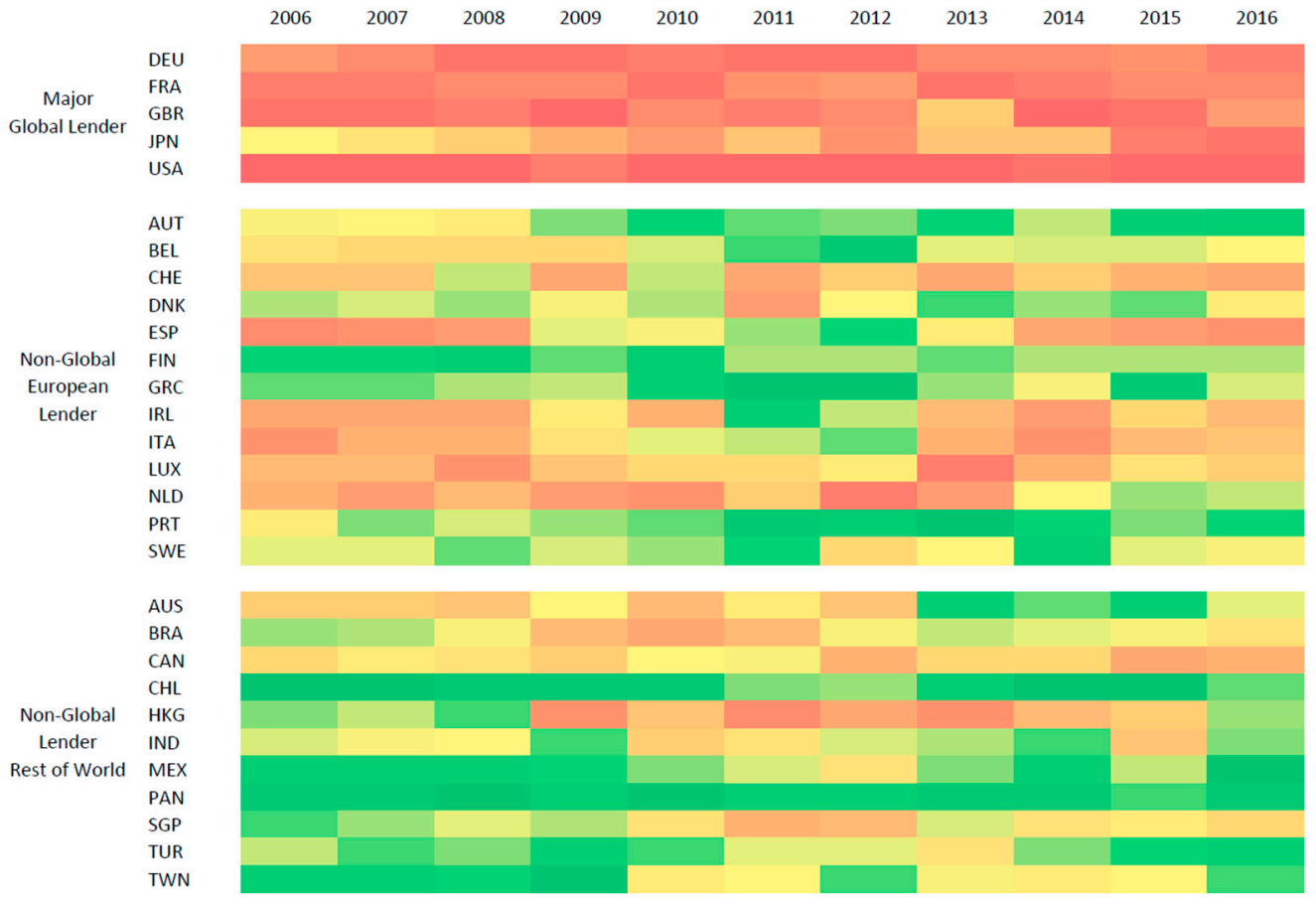

(b) Cross-Border Claims

\section{Figure 14. Lenders' Katz-Bonacich Centrality Rank}

Note: Figure 14 plots the heatmaps showing the rank distribution of lenders' Katz-Bonacich centrality, at annual frequency. A low rank corresponds to high importance measures and a red color. A high rank corresponds to low importance and a blue color. A number of lenders have zero local claims after adjustment. 
fraction of edges in the given division and the fraction in an equivalent network with randomly configured edges.

Here, instead of optimizing modularity to find clusters in the network (a recent example in the literature includes Greenhill and Lupu (2017), who finds that the intergovernmental organization network has become less fragmented) we use modularity as a quality indicator. Given a division of countries according to their regions, higher modularity implies that the network is better characterized as being regionalized, as the clustering into regions is stronger. For each period, we calculate the modularity, $Q_{A_{t}}$, of the baseline network $A_{t}$ using the Leicht and Newman (2008) extension of modularity to weighted, directed networks, as the following:

$$
Q_{A_{t}}=\frac{1}{m} \sum_{i j}\left[A_{i j}-\frac{s_{i}^{\text {in }} s_{j}^{\text {out }}}{m}\right] \delta_{c_{i}, c_{j}}
$$

where $m$ is the total edge weights $\left(m=\sum_{i j} A_{i j}\right) . s_{i}^{\text {in }}$ and $s_{j}^{\text {out }}$ represent the in-strength and outstrength of node $i$ and $j$, respectively. Finally, given a function $c(\cdot)$ that takes a node as input and returns the group of the node, $\delta_{c_{i}, c_{j}}$ is the Kronecker delta function.

We impose two regional divisions on our baseline network, using UN continental regions and sub-regions classification. Figure 15 plots the evolution of network modularity, clearly

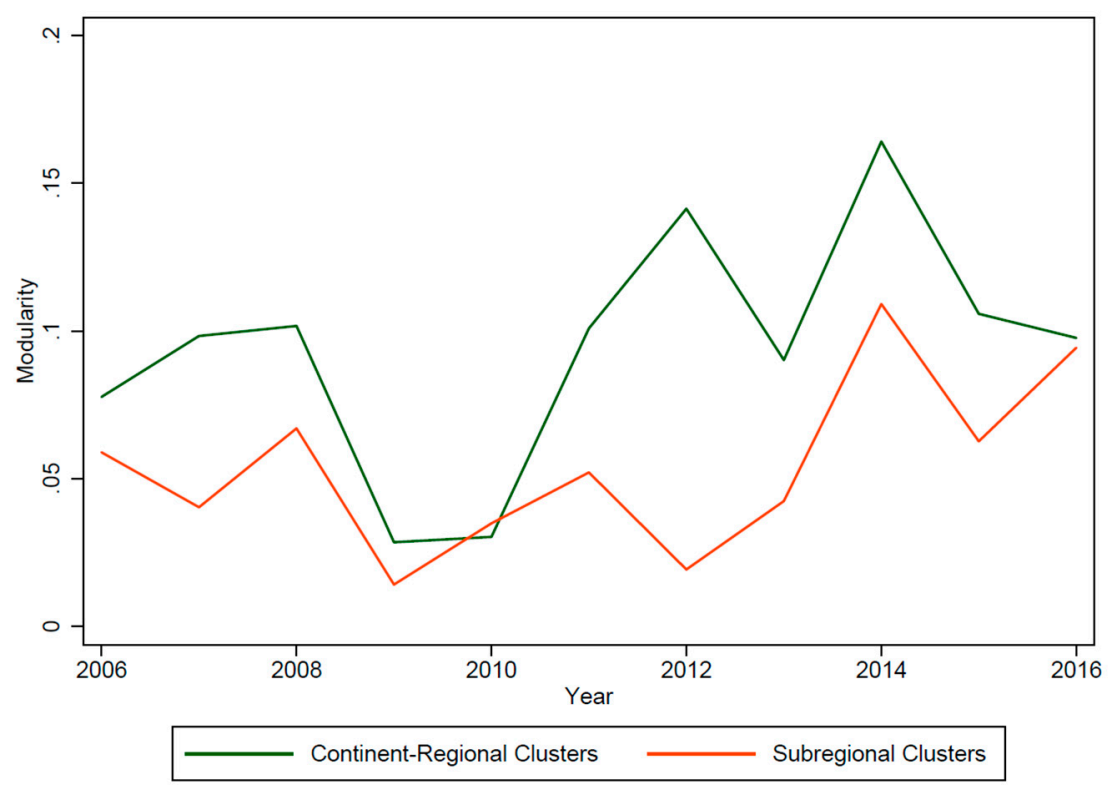

Figure 15. Evolution of Network Modularity for Regional Clusters

Note: the quarterly series are annualized by taking $4 \mathrm{Q}$ average. Regional clusters and subregional clusters refer to UN classification of continental regions and subregions, respectively. Calculation of modularity follows the definition in Section 3. 


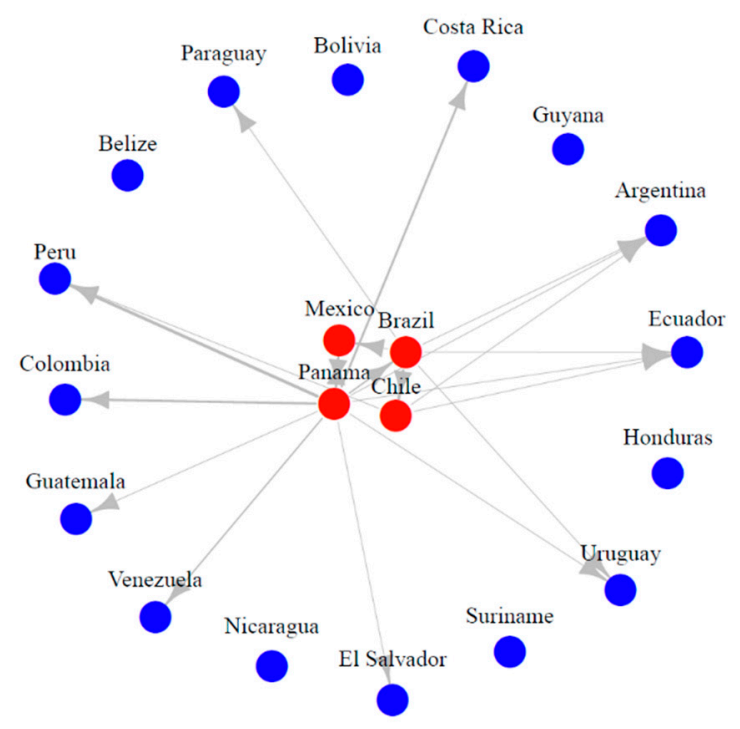

(a) Cross-Border Flows: 2007Q4

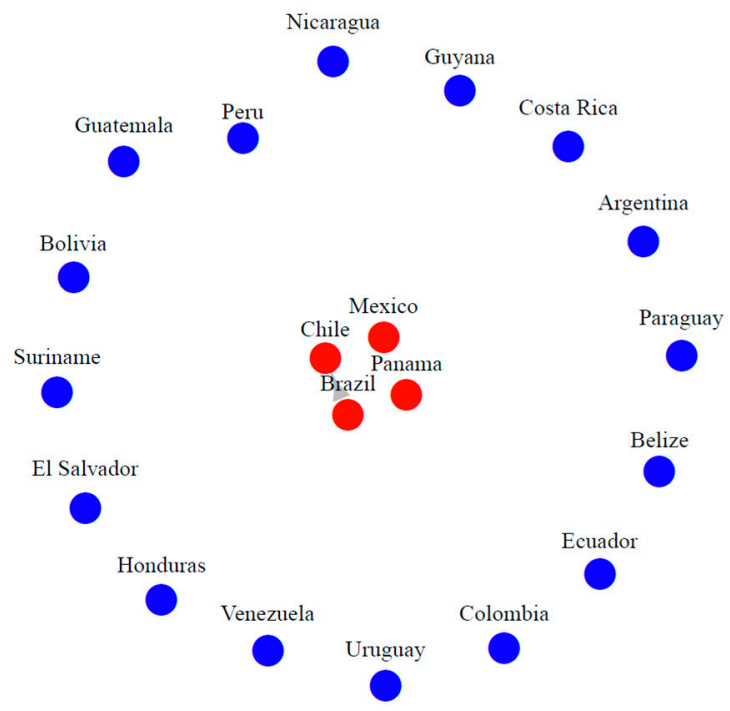

(c) Local Flows: 2007Q4

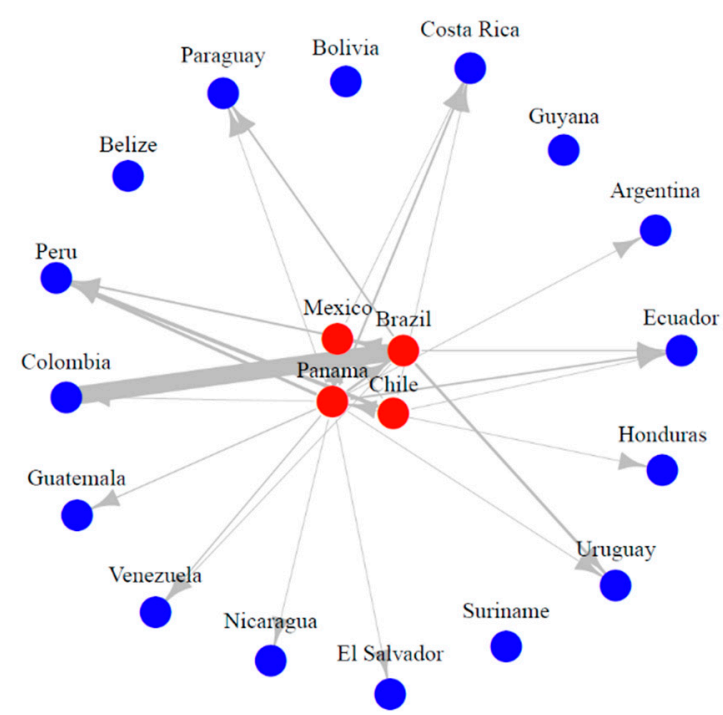

(b) Cross-Border Flows: 2014Q4

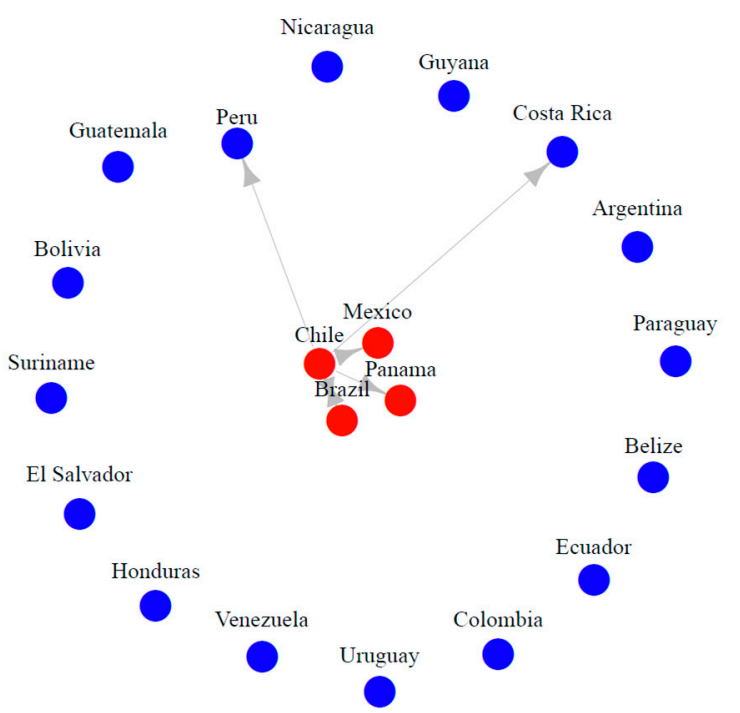

(d) Local Flows: 2014Q4

Figure 16. Latin-America: Within-Region Banking Flows

Note: Figures are plotted using Fruchterman-Reingold algorithm. Red nodes denote reporting countries. Size of arrows represent strength of connection while the presence of connection between two countries is governed by whether there is a positive change between the reporting country's current exposure and the exposure four quarters earlier to the counterparty. Definition of connection and strength follows the network construction outlined in Section 2.1.

showing an increase in the level of modularity for both divisions, with most increase starting from 2010. Countries form strong within-region cross-border banking connections rather than global ones, and such a trend seems more pronounced as we move to finer regional classifications (sub-region). This exercise, as a result, offers the most direct evidence 
showing that the degree of regionalization, as a form of fragmentation in the network, rises significantly after the crisis.

Figure 16 illustrates the regionalization pattern by plotting the sub-network of Latin American and Caribbean countries. Before the crisis (2007Q4), cross-border flows dominate the banking linkages within the region, while flows from local subsidiary are small in magnitude and mostly restricted within reporting countries. Within-region connections in 2014Q4, on the other hand, have become significantly denser and stronger for both crossborder and local flows, with reporting countries increasing their exposure to a number of non-reporting countries, such as Colombia and Peru.

\section{Regression Analysis}

The rise in network-based measures for many non-global lenders after the crisis suggests that the regionalization process is potentially driven by these countries that are consolidating their status as key regional players in the banking network. We test this hypothesis by running a set of regressions following the literature on the determinants of international financial flows and cross-border banking (Papaioannou, 2009; Claessens and van Horen, 2012; Cerutti, Hale and Minoiu, 2016). More specifically, we estimate the following specification:

$$
\log _{\text {Flow }} \text { ijt }=\beta_{0}+\beta_{1} X_{i t}+\beta_{2} Y_{j t}+\beta_{2} Z_{i j t}+\alpha_{i}+\gamma_{j}+\delta_{t}+\varepsilon_{i j t}
$$

where $X_{i t}$ denotes lender characteristics, $Y_{j t}$ represents borrower characteristics and $Z_{i j t}$ contains the lender-borrower mutual linkages. $\alpha_{i}, \gamma_{j}$ and $\delta_{t}$ are lender, borrower and time fixed effects, respectively. Regressing on log flows allows us to interpret the coefficients as elasticities. For bilateral linkages, we use geographical distance and lender's export to borrower as a share of total export, as well as a dummy variable with a value of 1 when borrower and lender are from a common region/sub-region - our main variable of interest. Table 1 lists all reporting countries and their regional classification according to United Nationals M49 standard. ${ }^{19}$ Non-reporting countries' regional affiliations are similarly assigned. To decompose the potential regional effect into pre-crisis, crisis and post-crisis segments, we interact the common region variable with a crisis dummy (with value one if the connection is during 2008Q1 to 2009Q2) and a post-crisis dummy (assigned value one if date is later than 2009Q2). We include lender countries' bank size (proxied as average assets to GDP), credit to GDP ratio and credit outflow restrictions in our list of lender characteristics. For borrowers, a similar set of institutional and openness variables are included. Table 2 provides the summary statistics and the data sources of variables used in the regressions. Our sample is restricted to 2006 to 2013 due to data availability for a number of independent variables (e.g., capital flow restrictions).

We estimate the equation using ordinary least squares and report our results in Tables 3 and 4 , which provide estimates on lender, borrower and within-pair characteristics. Intensity of

\footnotetext{
${ }^{19}$ The standard is available at https://unstats.un.org/unsd/methodology/m49/. We adopt the continental regions as our region variable. Sub-region is the level immediately below continental regions, but above the intermediary regions.
} 
both cross-border and local linkages rises with geographical proximity and borrower's degree of development, as measured by GDP per capita. Cross-border flows are larger to borrowers with high credit to GDP ratios and a favorable institutional environment. The flows of local claims, on the other hand, increase with lender's banking system development proxied by banking assets to GDP ratio, as larger banks are more likely to go global by opening branches and/or acquiring subsidiaries. The coefficient on lender outflow restriction is large and highly significant for local flows, suggesting local affiliates as the potential means to circumvent parent country regulatory barriers. Finally, the significant, positive coefficient on lender share of export to borrower country seems to reflect trade-finance synchronization, while cross-border lending seems to have little correlation with this trade related variable.

More importantly, the analysis in Tables 3 and 4 reveals that even after controlling for geographical distance, several coefficients on common region/sub-region and their interactions are large and significant. This is especially the case of peripheral (non-global, non-European) lenders, which seem to have lent cross-border more to countries within the same region even before the crisis. After the crisis, the regionalization process accelerates for both cross-border and local flows. The coefficients of the triple interaction with post-crisis and peripheral lenders are positive and significant for both cross-border and local flows. This finding adds to our network-based observation that regional preference emerges as one additional determinant of the evolution of global banking after the crisis. While the Euro Area experienced a large negative shock to its regional financial linkages, peripheral lenders help drive the regional integration in other regions.

\section{Robustness}

\section{Cross-Dataset Comparison}

In this section, we report results of our robustness check. We compare our results with those obtained from similar analysis, using BIS Locational Banking Statistics (FX-adjusted flow), Consolidated Banking Statistics, and exchange rate adjusted cross-border flows to underscore the significant role data difference plays in analyzing country-level cross-border lending. We further adjust our baseline data for break-in-series and exchange rate variation using the method in Cerutti (2015), resulting in a shorter sample period (2007Q1-2011Q3), but is still able to capture post-crisis dynamics. To ensure consistency, we define banking flows for all datasets using the same rolling four-quarter difference as we define the baseline network.

Figure 17 plots the average in-degree and in-strength for the three alternative datasets, confirming an overall shrinkage of cross-border banking. We further calculate, for each country in the network, Katz-Bonacich centrality and authority/hub measure of node importance. To compare the validity of node-level network metrics, we calculate the crossdataset correlation of node-level measures and compare the correlation between the skewness of authority measure and mean in-strength. Table 5 displays the results. Our node-level network metrics exhibit moderate-to-high level of correlation across CBS-based datasets, but 
correlation with the LBS dataset is weaker. The weak correlation persists even after we delete, from the LBS data, lenders who do not report CBS data. Cross-dataset analysis thus reveals that, while methodological differences and reporting issues have a minor impact on aggregate banking statistics, the relative position of individual countries within the banking network may be distorted, thus making the accurate selection of surveillance dataset targets a difficult endeavor.

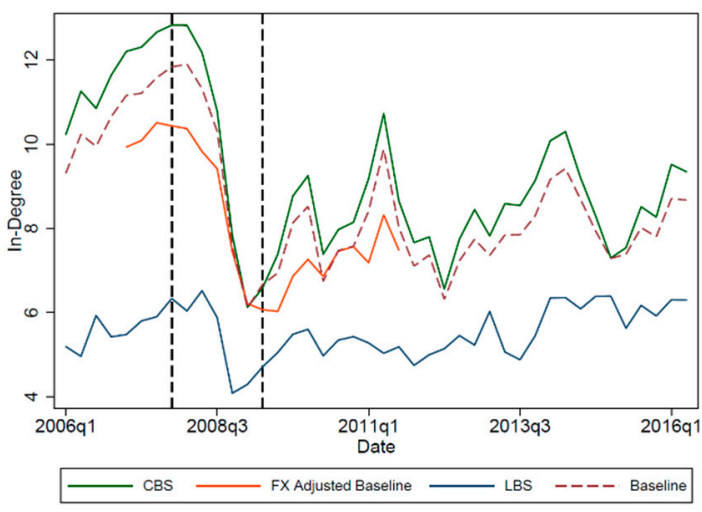

(a) In-Degree

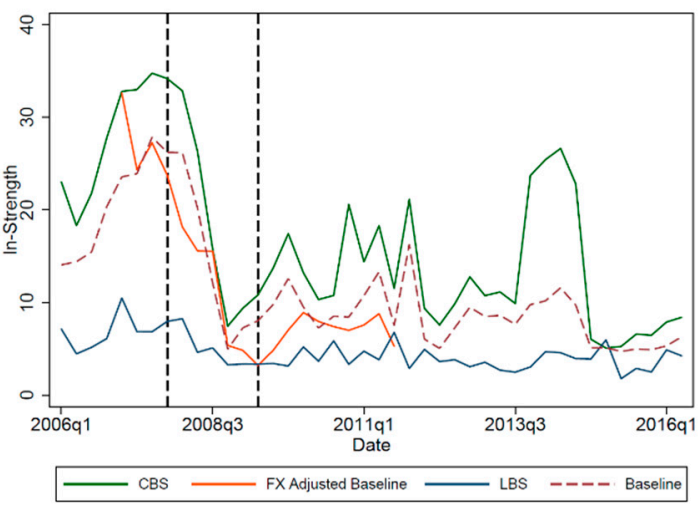

(b) In-Strength

Figure 17. In-Degree and In-Strength: Alternative Data

Note: Figure 17 plots the mean in-degree and in-strength of the networks constructed using LBS (public), CBS and exchange rate adjusted baseline data. The sample of reporting countries in the LBS data is kept the same as that in the baseline, CBS and exchange rate adjusted data. The exchange rate adjusted data lasts from $2007 \mathrm{Q} 1$ to 2011Q3.

\section{Alternative Measure of Cross-Border Banking Flows}

The four-quarter difference definition of banking flows addresses the concern that the quarter-on-quarter variation in total claims may capture seasonality patterns and reflect exchange rate short-term variation from the previous quarter. As an alternative, we define the baseline adjacency matrix based on one-quarter absolute change of adjusted CBS total claims. This definition complies more closely with the intuitive notion of quarterly flows.

$$
A_{i j t}=\max \left(\Delta U_{i j t}^{\text {adjusted }}, 0\right)=\max \left(U_{i j t}^{\text {adjusted }}-U_{i j(t-1)}^{\text {adjusted }}, 0\right)
$$

Figure 18 summarizes general properties of the alternative networks. This alternative definition is able to replicate overall patterns of evolution of key network indicators. However, the anticipated large volatility of the indicators might mask interesting trend in the dynamics of the indicators. It is thus not recommended to calculate cross-border flows from 
the change in exposure without accounting for exchange rate variation, especially during crisis episodes.
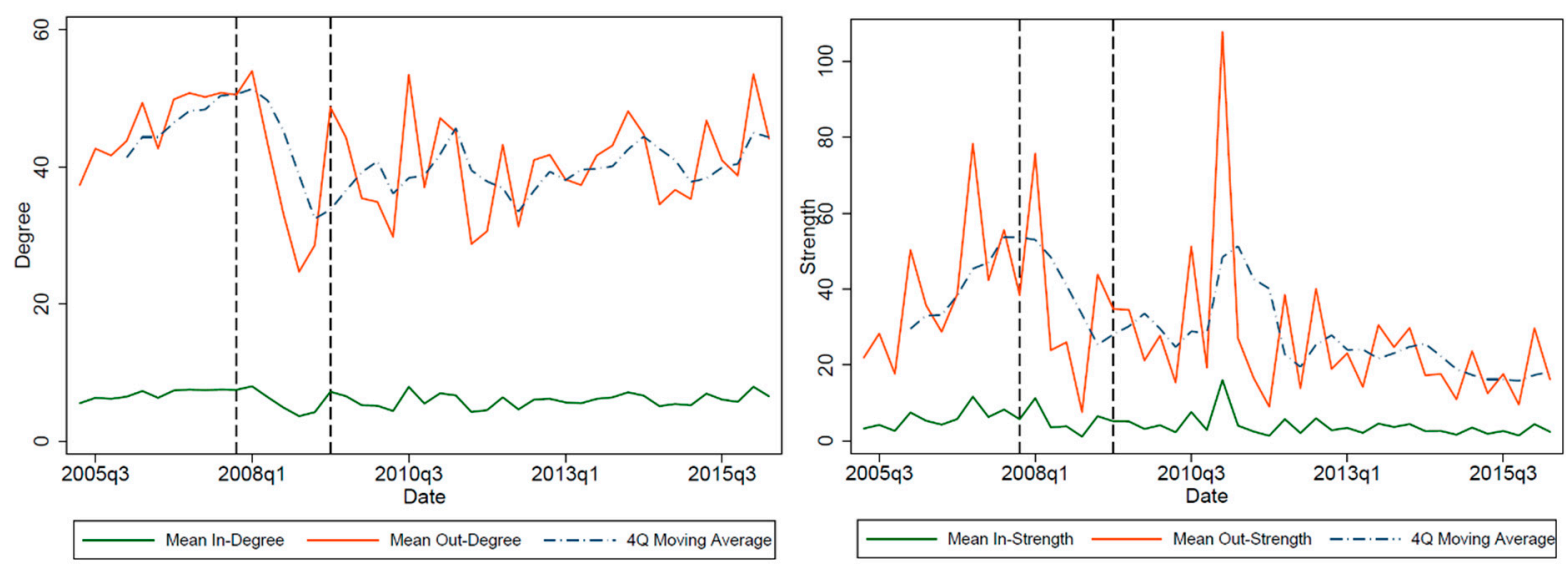

Figure 18. Average Degree and Strength: Alternative Measure

Note: Figure 18 plots the average degree and strength of the alternative networks. The alternative networks are constructed based on one-quarter difference of bilateral exposure.

\section{Conclusion}

In this paper, we map and characterize the dynamics of the global banking network. We show that without proper adjustment, country-level banking statistics suffer from multiple data issues that distort the actual role of each country in cross-border lending, and increase the difficulty of accurately detecting key players in the network. We find evidence confirming the overall shrinkage in the scale of cross-border bank lending using a variety of network analysis tools. Moreover, these methods capture rich dynamics that occur inside the global banking network and are not captured by traditional aggregate indicators.

Using a set of centrality measures with meaningful economic interpretations, we delve substantially deeper to capture the interconnectedness faced by each country. While the structural stability of the highly concentrated global banking network is mainly due to the stability of major global lenders, we observe decline in importance for non-major global European lenders and a corresponding rise in the ranks for lenders from other region, comprised of mostly emerging market lenders. The hidden dynamics of the global banking network after the crisis suggest that the assertion that cross-border lending has shrunk globally seems to miss out significant details. Rather, our findings are more consistent with the recent observation during a lecture by Caruana (2017), based on McCauley et al (2017), that financial de-globalization may be more a feature of retrenchment in Europe rather than global banking. Given the strong banking linkages among European countries, the declining 
importance of European lenders can only be partially offset by emerging lenders, resulting in an overall slowdown in cross-border lending activities. Such slowdown, however, does not necessarily indicate a general retrenchment across the globe, despite the fact that decreasing financial interconnectedness may have come at a cost (e.g., global banks' connections contribute to the allocation of worldwide global savings).

Using network analysis methods, we also find a clear upward trend in the level of regional fragmentation of the banking network, especially in the periphery of the global banking network. This phenomenon is further supported by regression analysis, even after controlling for geographical distance, among a broad set of determinants of international banking. Moreover, given the nature of the BIS sample used that does not include China and South Korea, and other potential small recent regional lenders as Colombia, our findings of the presence of regionalization in both direct cross-border and affiliates' local lending is reassuring since the sample used in our calculations is biased against this phenomenon. ${ }^{20}$

While the measure reveals the underlying structural transformation of the global banking network in a positive manner, the systemic risk implication of this finding is not as clear. Using only aggregate data, we refrain from making detailed arguments on systemic risk. But in general, an increasingly regionalized pattern of global banking may to some degree prevent the propagation of shocks across the globe, while increasing the intensity that a regional shock is shared within-region. Our measurement of network fragmentation is closely related to academic and policy debates such as Haldane (2010) who argues that fragmented structures can strengthen system resilience. This notion is further rationalized in Elliott and Hazell (2016) that modular structures could be socially efficient in an endogenous financial network. However, Elliott and Hazell (2016) also indicates that such structures may not be stable. More research effort is thus needed to investigate the relationship between regionalization and risk in the global banking system, explanations of the structural change, and implications for macroprudential policy-making and surveillance.

\footnotetext{
${ }^{20}$ Our adjustment to the data cannot overcome constraints imposed by incomplete data reporting. Korea, for example, did not join as a BIS CBS reporting country until 2013, China only started to report LBS since 2016Q4, Colombia is a not a reporting country. Available data for Korea and China suggests a strong crossborder lending presence in Asia, and IMF (2017) highlights the recent expansion of Colombian banks in Central America.
} 


\begin{tabular}{|c|c|c|}
\hline Reporting Countries & Country & Region (UN) \\
\hline \multirow{5}{*}{ Major Global Lenders } & United States & Americas \\
\hline & Japan & Asia \\
\hline & France & Europe \\
\hline & Germany & Europe \\
\hline & United Kingdom & Europe \\
\hline \multirow{13}{*}{$\begin{array}{l}\text { Non-Global European } \\
\text { Lenders }\end{array}$} & Austria & Europe \\
\hline & Belgium & Europe \\
\hline & Denmark & Europe \\
\hline & Finland & Europe \\
\hline & Greece & Europe \\
\hline & Ireland & Europe \\
\hline & Italy & Europe \\
\hline & Luxembourg & Europe \\
\hline & Netherlands & Europe \\
\hline & Portugal & Europe \\
\hline & Spain & Europe \\
\hline & Sweden & Europe \\
\hline & Switzerland & Europe \\
\hline \multirow{11}{*}{$\begin{array}{l}\text { Non-Global Lenders, Rest } \\
\text { of World }\end{array}$} & Australia & Oceania \\
\hline & Brazil & Americas \\
\hline & Canada & Americas \\
\hline & Chile & Americas \\
\hline & Mexico & Americas \\
\hline & Panama & Americas \\
\hline & Hong Kong SAR & Asia \\
\hline & India & Asia \\
\hline & Singapore & Asia \\
\hline & Taiwan Province of China & Asia \\
\hline & Turkey & Asia \\
\hline Non-reporting Countries & \multicolumn{2}{|c|}{ Definition } \\
\hline Non-reporting AEs & \multicolumn{2}{|c|}{$\begin{array}{l}\text { Advanced economies per IMF definition not reporting BIS CBS } \\
\text { data. South Korea is included in this category to maintain a } \\
\text { constant lender composition. }\end{array}$} \\
\hline Non-reporting EMs & \multicolumn{2}{|c|}{$\begin{array}{l}\text { Emerging market economies per IMF definition not reporting BIS } \\
\text { CBS data. }\end{array}$} \\
\hline Offshore Financial Centers & \multicolumn{2}{|c|}{$\begin{array}{l}\text { Offshore financial centers per IMF definition not reporting BIS } \\
\text { CBS data. }\end{array}$} \\
\hline Peripheral Countries & \multicolumn{2}{|c|}{ Countries not included in any other categories. } \\
\hline
\end{tabular}

Table 1. Country Definitions and Regional Classifications 


\begin{tabular}{|c|c|c|c|c|c|c|}
\hline & $\mathbf{N}$ & Mean & SD & Min & Max & Source/Note \\
\hline \multicolumn{7}{|l|}{$\underline{\text { Flows }}$} \\
\hline Log Cross-Border Flows & 54845 & -2.93 & 2.79 & -13.82 & 6.55 & BIS \\
\hline Log Local Flows & 15682 & -3.56 & 3.46 & -19.12 & 5.70 & BIS \\
\hline \multicolumn{7}{|l|}{ Mutual Linkages: } \\
\hline Common Region & 257462 & 0.22 & 0.41 & 0 & 1 & United Nations \\
\hline Log Geographical Distance & 257462 & 8.70 & 0.82 & 4.18 & 9.90 & CEPII GeoDist \\
\hline $\begin{array}{l}\text { Lender Export to Borrower } \\
\text { (Share of Total Export) }\end{array}$ & 235106 & 0.54 & 2.54 & 0.00 & 86.52 & Direction of Trade Statistics \\
\hline \multicolumn{7}{|l|}{ Lender Characteristics: } \\
\hline Lender Overall Outflow Restriction & 187596 & 0.20 & 0.26 & 0 & 1 & Fernandez et al. (2017) \\
\hline Lender Bank Assets to GDP & 211528 & 116.42 & 45.66 & 24.38 & 257.42 & World Bank \\
\hline Lender Credit to GDP & 251672 & 102.11 & 53.49 & 0.09 & 298.10 & $\begin{array}{l}\text { International Financial } \\
\text { Statistics }\end{array}$ \\
\hline Lender Log GDP per capita & 235074 & 10.28 & 0.90 & 6.61 & 11.67 & World Bank \\
\hline \multicolumn{7}{|l|}{ Borrower Characteristics: } \\
\hline Borrower Overall Inflow Restriction & 103428 & 0.34 & 0.31 & 0 & 1 & Fernandez et al. (2017) \\
\hline Borrower Capital Account Openness & 197048 & 0.44 & 1.62 & -1.89 & 2.39 & Chinn and Ito (2006) \\
\hline Borrower Institutional Quality & 181250 & 70.08 & 9.25 & 24.00 & 92.50 & $\begin{array}{l}\text { International Country Risk } \\
\text { Guide }\end{array}$ \\
\hline Borrower Credit to GDP & 228318 & 49.21 & 45.38 & 0.09 & 312.12 & $\begin{array}{l}\text { International Financial } \\
\text { Statistics }\end{array}$ \\
\hline Borrower Log GDP per capita & 221560 & 8.44 & 1.54 & 4.97 & 11.67 & World Bank \\
\hline
\end{tabular}

\section{Table 2. Summary Statistics for Regression}

Note: Institutional quality variable is taken from ICRG's composite risk rating. Higher index represents lower risk. Outflow and inflow restriction index is based on information from IMF Annual Report on Exchange Arrangements and Exchange Restrictions (AREAER). 


\begin{tabular}{|c|c|c|c|c|c|c|}
\hline \multirow{2}{*}{ N } & \multicolumn{3}{|c|}{ Cross-Border } & \multicolumn{3}{|c|}{ Local } \\
\hline & $(1)$ & $(2)$ & (3) & (4) & $(5)$ & $(6)$ \\
\hline Region & $\begin{array}{l}-0.0969 \\
(0.0970)\end{array}$ & $\begin{array}{l}-0.0520 \\
(0.101)\end{array}$ & $\begin{array}{l}-0.318 * * * \\
(0.117)\end{array}$ & $\begin{array}{l}-0.389 \\
(0.308)\end{array}$ & $\begin{array}{l}-0.485 \\
(0.322)\end{array}$ & $\begin{array}{l}-0.542 \\
(0.396)\end{array}$ \\
\hline Region * Post-Crisis & & $\begin{array}{l}-0.0736 \\
(0.0731)\end{array}$ & $\begin{array}{l}-0.169 * * \\
(0.0846)\end{array}$ & & $\begin{array}{l}0.0466 \\
(0.182)\end{array}$ & $\begin{array}{l}-0.0854 \\
(0.188)\end{array}$ \\
\hline Region * Crisis & & $\begin{array}{l}-0.0613 \\
(0.0660)\end{array}$ & $\begin{array}{l}-0.0639 \\
(0.0728)\end{array}$ & & $\begin{array}{l}0.306^{*} \\
(0.159)\end{array}$ & $\begin{array}{l}0.292^{*} \\
(0.163)\end{array}$ \\
\hline Region $*$ Peripheral $*$ Post-Crisis & & & $\begin{array}{l}0.278^{* *} \\
(0.136)\end{array}$ & & & $\begin{array}{l}0.928^{*} \\
(0.491)\end{array}$ \\
\hline Region $*$ Peripheral $*$ Crisis & & & $\begin{array}{l}-0.00421 \\
(0.120)\end{array}$ & & & $\begin{array}{l}0.224 \\
(0.434)\end{array}$ \\
\hline Log Distance & $\begin{array}{l}-1.030 * * * \\
(0.0710)\end{array}$ & $\begin{array}{l}-1.031 * * * \\
(0.0711)\end{array}$ & $\begin{array}{l}-1.010 * * * \\
(0.0718)\end{array}$ & $\begin{array}{l}-1.500 * * * \\
(0.225)\end{array}$ & $\begin{array}{l}-1.504 * * * \\
(0.225)\end{array}$ & $\begin{array}{l}-1.517 * * * \\
(0.231)\end{array}$ \\
\hline$\overline{\text { Lender Outflow Restriction }}$ & $\begin{array}{l}0.243 \\
(0.245)\end{array}$ & $\begin{array}{l}0.251 \\
(0.245)\end{array}$ & $\begin{array}{l}0.183 \\
(0.242)\end{array}$ & $\begin{array}{l}2.070 * * * \\
(0.716)\end{array}$ & $\begin{array}{l}2.064 * * * \\
(0.715)\end{array}$ & $\begin{array}{l}1.811^{* *} \\
(0.704)\end{array}$ \\
\hline Lender Bank Assets to GDP & $\begin{array}{l}-0.00126 \\
(0.00217)\end{array}$ & $\begin{array}{l}-0.00126 \\
(0.00217)\end{array}$ & $\begin{array}{l}-0.000862 \\
(0.00218)\end{array}$ & $\begin{array}{l}0.0249 * * * \\
(0.00685)\end{array}$ & $\begin{array}{l}0.0252 * * * \\
(0.00686)\end{array}$ & $\begin{array}{l}0.0258 * * * \\
(0.00691)\end{array}$ \\
\hline Lender Credit to GDP & $\begin{array}{l}0.0124 * * * \\
(0.00281)\end{array}$ & $\begin{array}{l}0.0124 * * * \\
(0.00281)\end{array}$ & $\begin{array}{l}0.0115 * * * \\
(0.00284)\end{array}$ & $\begin{array}{l}-0.0171^{* * * *} \\
(0.00621)\end{array}$ & $\begin{array}{l}-0.0171 * * * \\
(0.00626)\end{array}$ & $\begin{array}{l}-0.0170 * * * \\
(0.00634)\end{array}$ \\
\hline Lender Log GDP per capita & $\begin{array}{l}0.742 * * * \\
(0.161)\end{array}$ & $\begin{array}{l}0.744 * * * \\
(0.161)\end{array}$ & $\begin{array}{l}0.660^{* * *} \\
(0.169)\end{array}$ & $\begin{array}{l}0.874 \\
(0.540)\end{array}$ & $\begin{array}{l}0.832 \\
(0.544)\end{array}$ & $\begin{array}{l}0.492 \\
(0.520)\end{array}$ \\
\hline \multicolumn{7}{|l|}{ Borrower Characteristics: } \\
\hline$\overline{\text { Borrower Inflow Restriction }}$ & $\begin{array}{l}0.187 \\
(0.199)\end{array}$ & $\begin{array}{l}0.178 \\
(0.199)\end{array}$ & $\begin{array}{l}0.181 \\
(0.200)\end{array}$ & $\begin{array}{l}0.838 \\
(0.804)\end{array}$ & $\begin{array}{l}0.871 \\
(0.800)\end{array}$ & $\begin{array}{l}0.815 \\
(0.792)\end{array}$ \\
\hline Borrower Capital Account Openness & $\begin{array}{l}-0.0230 \\
(0.0502)\end{array}$ & $\begin{array}{l}-0.0235 \\
(0.0503)\end{array}$ & $\begin{array}{l}-0.0179 \\
(0.0501)\end{array}$ & $\begin{array}{l}-0.0212 \\
(0.172)\end{array}$ & $\begin{array}{l}0.00237 \\
(0.174)\end{array}$ & $\begin{array}{l}0.0126 \\
(0.172)\end{array}$ \\
\hline
\end{tabular}

Table 3. Regionalization of global banking - Regression with other determinants and crisis interactions, region level

Note: Standard errors are clustered at country-pair level. ***: significant at $1 \%$ level; **: significant at $5 \%$ level; *: significant at $10 \%$ level. "Peripheral" refers to BIS reporting countries classified as "Non-Global, Rest of World" countries in Table 1. Constant term is not reported. 


\begin{tabular}{|c|c|c|c|c|c|c|}
\hline & \multicolumn{3}{|c|}{ Cross-Border } & \multicolumn{3}{|c|}{ Local } \\
\hline & $(1)$ & $(2)$ & (3) & (4) & $(5)$ & $(6)$ \\
\hline \multicolumn{7}{|l|}{ Mutual Linkages: } \\
\hline Sub-region & $\begin{array}{l}-0.0540 \\
(0.126)\end{array}$ & $\begin{array}{l}-0.190 \\
(0.134)\end{array}$ & $\begin{array}{l}-0.386^{* *} \\
(0.152)\end{array}$ & $\begin{array}{l}0.195 \\
(0.310)\end{array}$ & $\begin{array}{l}0.390 \\
(0.347)\end{array}$ & $\begin{array}{l}0.462 \\
(0.360)\end{array}$ \\
\hline Sub-region * Post-Crisis & & $\begin{array}{l}0.279 * * \\
(0.116)\end{array}$ & $\begin{array}{l}0.0527 \\
(0.142)\end{array}$ & & $\begin{array}{l}-0.276 \\
(0.347)\end{array}$ & $\begin{array}{l}-0.626^{*} \\
(0.368)\end{array}$ \\
\hline Sub-region $*$ Crisis & & $\begin{array}{l}0.0230 \\
(0.114)\end{array}$ & $\begin{array}{l}-0.146 \\
(0.139)\end{array}$ & & $\begin{array}{l}-0.324 \\
(0.226)\end{array}$ & $\begin{array}{l}-0.401^{*} \\
(0.243)\end{array}$ \\
\hline Sub-region $*$ Peripheral & & & $\begin{array}{l}0.753 * * * \\
(0.260)\end{array}$ & & & $\begin{array}{l}-0.614 \\
(1.149)\end{array}$ \\
\hline Sub-region $*$ Peripheral $*$ Post-Crisis & & & $\begin{array}{l}0.352 \\
(0.244)\end{array}$ & & & $\begin{array}{l}1.810^{*} \\
(1.033)\end{array}$ \\
\hline Sub-region $*$ Peripheral $*$ Crisis & & & $\begin{array}{l}0.360 \\
(0.225)\end{array}$ & & & $\begin{array}{l}0.658 \\
(0.609)\end{array}$ \\
\hline Log Distance & $\begin{array}{l}-0.996^{* * *} \\
(0.0534)\end{array}$ & $\begin{array}{l}-0.994 * * * \\
(0.0533)\end{array}$ & $\begin{array}{l}-0.959 * * * \\
(0.0542)\end{array}$ & $\begin{array}{l}-1.295^{* * *} \\
(0.164)\end{array}$ & $\begin{array}{l}-1.296^{* * * *} \\
(0.164)\end{array}$ & $\begin{array}{l}-1.272 * * * \\
(0.164)\end{array}$ \\
\hline Lender Share of Export to Borrower & $\begin{array}{l}0.0143 \\
(0.0109)\end{array}$ & $\begin{array}{l}0.0149 \\
(0.0109)\end{array}$ & $\begin{array}{l}0.0165 \\
(0.0103)\end{array}$ & $\begin{array}{l}0.0893 * * * \\
(0.0293)\end{array}$ & $\begin{array}{l}0.0884 * * * \\
(0.0294)\end{array}$ & $\begin{array}{l}0.0922 * * * \\
(0.0298)\end{array}$ \\
\hline \multicolumn{7}{|l|}{ Lender Characteristics: } \\
\hline$\overline{\text { Lender Outflow Restriction }}$ & $\begin{array}{l}0.234 \\
(0.245)\end{array}$ & $\begin{array}{l}0.191 \\
(0.244)\end{array}$ & $\begin{array}{l}0.167 \\
(0.242)\end{array}$ & $\begin{array}{l}2.057 * * * \\
(0.719)\end{array}$ & $\begin{array}{l}2.066^{* * *} \\
(0.721)\end{array}$ & $\begin{array}{l}1.875 * * * \\
(0.712)\end{array}$ \\
\hline Lender Bank Assets to GDP & $\begin{array}{l}-0.00131 \\
(0.00217)\end{array}$ & $\begin{array}{l}-0.00122 \\
(0.00217)\end{array}$ & $\begin{array}{l}-0.00114 \\
(0.00217)\end{array}$ & $\begin{array}{l}0.0248 * * * \\
(0.00685)\end{array}$ & $\begin{array}{l}0.0246^{* * * *} \\
(0.00686)\end{array}$ & $\begin{array}{l}0.0243 * * * \\
(0.00687)\end{array}$ \\
\hline Lender Credit to GDP & $\begin{array}{l}0.0124 * * * \\
(0.00281)\end{array}$ & $\begin{array}{l}0.0123 * * * \\
(0.00281)\end{array}$ & $\begin{array}{l}0.0121 * * * \\
(0.00281)\end{array}$ & $\begin{array}{l}-0.0172 * * * \\
(0.00621)\end{array}$ & $\begin{array}{l}-0.0169 * * * \\
(0.00621)\end{array}$ & $\begin{array}{l}-0.0163 * * * \\
(0.00623)\end{array}$ \\
\hline Lender Log GDP per Capita & $\begin{array}{l}0.740 * * * \\
(0.161)\end{array}$ & $\begin{array}{l}0.726^{* * *} \\
(0.160)\end{array}$ & $\begin{array}{l}0.710^{* * *} \\
(0.161)\end{array}$ & $\begin{array}{l}0.891 \\
(0.545)\end{array}$ & $\begin{array}{l}0.898 \\
(0.548)\end{array}$ & $\begin{array}{l}0.700 \\
(0.514)\end{array}$ \\
\hline \multicolumn{7}{|l|}{ Borrower Characteristics: } \\
\hline$\overline{\text { Borrower Inflow Restriction }}$ & $\begin{array}{l}0.188 \\
(0.199)\end{array}$ & $\begin{array}{l}0.179 \\
(0.198)\end{array}$ & $\begin{array}{l}0.179 \\
(0.196)\end{array}$ & $\begin{array}{l}0.827 \\
(0.804)\end{array}$ & $\begin{array}{l}0.838 \\
(0.805)\end{array}$ & $\begin{array}{l}0.777 \\
(0.801)\end{array}$ \\
\hline Borrower Capital Account Openness & $\begin{array}{l}-0.0220 \\
(0.0501)\end{array}$ & $\begin{array}{l}-0.0195 \\
(0.0500)\end{array}$ & $\begin{array}{l}-0.0248 \\
(0.0500)\end{array}$ & $\begin{array}{l}-0.00826 \\
(0.170)\end{array}$ & $\begin{array}{l}-0.0163 \\
(0.171)\end{array}$ & $\begin{array}{l}-0.000729 \\
(0.168)\end{array}$ \\
\hline Borrower Institutional Quality & $\begin{array}{l}0.0253 * * * \\
(0.00633)\end{array}$ & $\begin{array}{l}0.0255^{* * * *} \\
(0.00632)\end{array}$ & $\begin{array}{l}0.0247 * * * \\
(0.00631)\end{array}$ & $\begin{array}{l}0.0150 \\
(0.0182)\end{array}$ & $\begin{array}{l}0.0150 \\
(0.0182)\end{array}$ & $\begin{array}{l}0.0114 \\
(0.0183)\end{array}$ \\
\hline Borrower Credit to GDP & $\begin{array}{l}0.00617 * * * \\
(0.00138)\end{array}$ & $\begin{array}{l}0.00625^{* * *} \\
(0.00138)\end{array}$ & $\begin{array}{l}0.00622 * * * \\
(0.00137)\end{array}$ & $\begin{array}{l}0.00752^{*} \\
(0.00418)\end{array}$ & $\begin{array}{l}0.00760^{*} \\
(0.00419)\end{array}$ & $\begin{array}{l}0.00776^{*} \\
(0.00422)\end{array}$ \\
\hline Borrower Log GDP per Capita & $\begin{array}{l}0.676^{* * *} \\
(0.120)\end{array}$ & $\begin{array}{l}0.693 * * * \\
(0.120)\end{array}$ & $\begin{array}{l}0.664 * * * \\
(0.120)\end{array}$ & $\begin{array}{l}1.079 * * * \\
(0.345)\end{array}$ & $\begin{array}{l}1.060 * * * \\
(0.348)\end{array}$ & $\begin{array}{l}0.972 * * * \\
(0.349)\end{array}$ \\
\hline Observations & 26080 & 26080 & 26080 & 8974 & 8974 & 8974 \\
\hline R-squared & 0.681 & 0.681 & 0.683 & 0.547 & 0.547 & 0.548 \\
\hline Lender and Borrower FE & YES & YES & YES & YES & YES & YES \\
\hline Quarter FE & YES & YES & YES & YES & YES & YES \\
\hline
\end{tabular}

\section{Table 4. Regionalization of global banking - Regression with other determinants and crisis interactions, sub-region level.}

Note: Standard errors are clustered at country-pair level. ***: significant at $1 \%$ level; **: significant at $5 \%$ level; *: significant at $10 \%$ level. "Peripheral" refers to BIS reporting countries classified as "Non-Global, Rest of World" countries in Table 1. Constant term is not reported. 


\begin{tabular}{lrrrr}
\hline & Baseline & LBS & CBS & FX Adjusted \\
\hline Baseline & 1 & & & \\
\hline LBS & 0.7905 & 1 & & \\
\hline CBS & 0.9864 & 0.7937 & 1 & \\
\hline FX Adjusted & 0.9351 & 0.7688 & 0.9338 & \\
\hline
\end{tabular}

(a) In-Degree Correlation

\begin{tabular}{lrrrr}
\hline & Baseline & LBS & CBS & FX Adjusted \\
\hline Baseline & 1 & & & \\
\hline LBS & 0.7527 & 1 & & \\
\hline CBS & 0.9536 & 0.7495 & 1 & \\
\hline FX Adjusted & 0.7248 & 0.6097 & 0.7690 & 1 \\
\hline
\end{tabular}

(b) In-Strength Correlation

\begin{tabular}{lrrrr}
\hline & Baseline & LBS & CBS & FX Adjusted \\
\hline Baseline & 1 & & & \\
\hline LBS & 0.4030 & 1 & & \\
\hline CBS & 0.8568 & 0.3958 & 1 & \\
\hline FX Adjusted & 0.6999 & 0.3971 & 0.6871 & 1 \\
\hline
\end{tabular}

(c) In-Herfindahl Index Correlation

\begin{tabular}{lrrrr}
\hline & Baseline & LBS & CBS & FX Adjusted \\
\hline Baseline & 1 & & & \\
\hline LBS & 0.7508 & 1 & & \\
\hline CBS & 0.9072 & 0.7440 & 1 & \\
\hline FX Adjusted & 0.7563 & 0.6599 & 0.7610 & 1 \\
\hline
\end{tabular}

(d) Katz-Bonacich Centrality Correlation

\begin{tabular}{lrrrr}
\hline & Baseline & LBS & CBS & FX Adjusted \\
\hline Baseline & 1 & & & \\
\hline LBS & 0.1573 & 1 & & \\
\hline CBS & 0.7223 & 0.1462 & 1 & \\
\hline FX Adjusted & 0.4313 & 0.1225 & 0.3970 & 1 \\
\hline
\end{tabular}

(e) Authority Measure Correlation - Share Network

Table 5. Cross-Dataset Comparison: Correlation of Network Measures

Note: Table 5 reports the pairwise correlation of network indicators across different sources of data. Baseline refers to the "adjusted CBS" used in the paper. LBS refers to Locational Banking Statistics (public), and CBS refers to unadjusted Consolidated Banking Statistics. FX Adjusted is the CBS data used in Cerutti (2015) that accounts for break-in-series and exchange rate variation, but with a shorter timespan (2007Q1-2011Q3). 


\section{REFERENCES}

Acemoglu, Daron, Ufuk Akcigit, and William Kerr. 2015. "Networks and the Macroeconomy: An Empirical Exploration." NBER Macroeconomics Annual.

Allen, Franklin, and Douglas Gale. 2000. "Financial Contagion." Journal of Political Economy 108: 1-33.

Alvers, Ivan, Stjin Ferrari, Pietro Franchini, Jean-Cyprien Heam, Pavol Jurca, Sam Langfield, Sebastiano Laviola, et al. 2013. "The Structure and Resilience of the European Interbank Market." Occasional Paper Series, European Systemic Risk Board.

Ballester, Coralio, Antoni Calvó-Armengol, and Yves Zenou. 2006. "Whoś Who in Networks. Wanted: The Key Player." Econometrica 74: 1403-1417.

Bank for International Settlements. 2014. "EME Banking systems and regional financial integration." CGFS Papers, Committee on the Global Financial System.

Bank for International Settlements. 2012. "Improving the BIS international banking statistics." CGFS Papers, Committee on the Global Financial System.

Bonacich, P. 1987. "Power and Centrality: A family of measures." American Jounal of Sociology 92: 1170-1182.

Bonacich, Phillip, and Paulette Lloyd. 2001. "Eigenvector-like measures of centrality for asymmetric relations." Social Networks 23: 191-201.

Borgatti, Stephen P. 2005. "Centrality and network flow." Social Networks 27: 55-71.

Caruana, Jaime. 2017. "Have we passed 'peak finance'?" Lecture, International Center for Monetary and Banking Studies.

Cerutti, Eugenio. 2015. "Drivers of cross-border banking exposures during the crisis." Journal of Banking and Finance 55: 340-357.

Cerutti, Eugenio, and Stjin Claessens. 2017. "The great cross-border bank deleveraging: Supply Constraints and Intro-Group Frictions." Review of Finance 21: 201-236.

Cerutti, Eugenio, Galina Hale, and Camelia Minoiu. 2015. "Financial crises and the composition of cross-border lending." Journal of International Money and Finance 52: 60-81.

Cerutti, Eugenio, Giovanni Dell'Ariccia, and Maria Soledad Martinez Peria. 2007. "How banks go abroad: Branches or subsidiaries?" Journal of Banking and Finance 31: 1669-1692.

Cerutti, Eugenio, Stjin Claessens, and P. McGuire. 2014. "Measuring Systemic Risks in a Global Banking Sector: What Can Available Data Tell Us and What More Data are Needed?" In Risk Topography: Systemic Risk and Macro Modeling, edited by Markus Brunnermeier and Arvind Krishnamurthy. NBER.

Chinazzi, Matteo, Giorgio Fagiolo, Javier Reyes, and Stefano Schiavo. 2013. "Post-mortem examination of the international financial network." Journal of Economic Dynamics and Control 37: 1692-1713.

Chinn, Menzie D., and Hiro Ito. 2006. "What Matters for Financial Development? Capital Controls, Institutions, and Interactions." Journal of Development Economics 81 (1): 163-192.

Claessens, Stijn, and Neeltje van Horen. 2012. "Being a foreigner among domestic banks: Asset or liability?" Journal of Banking and Finance 36 (5): 1276-1290.

Claessens, Stjin, and Neeltje van Horen. 2015. "The impact of the Global Financial Crisis on Banking Globalization." IMF Economic Review 63: 868-917. 
Denbee, Edward, Christian Julliard, Ye Li, and Kathy Yuan. 2016. "Network Risk and Key Players: A structural analysis of Interbank Liquidity." unpublished.

Elliott, Matthew, and Jonathon Hazell. 2016. "Endogenous Financial Networks: Efficient Modularity and Why Shareholders Prevent It." Working Paper.

European Central Bank. 2016. "Financial Integration in Europe." Tech. rep., Eurosystem. European Central Bank. 2015. "Financial Integration in Europe." Tech. rep., Eurosystem. European Central Bank. 2014. "Financial Integration in Europe." Tech. rep., Eurosystem. Fernandez, Andres, Michael Klein, Alessandro Rebucci, Martin Schindler, and Martin Uribe. 2016. "Capital Control Measures: A New Dataset." IMF Economic Review 64: 548574.

Forbes, Kristin. 2014. "Financial 'deglobalization'?: capital flows, banks and the Beatles." Speech, Bank of England.

Forbes, Kristin, Dennis Reinhardt, and Tomasz Wieladek. 2017. "The spillovers, interactions, and (un)intended consequences of monetary and regulatory policies." Journal of Monetary Economics 85: 1-22. doi:http://dx.doi.org/10.1016/j.jmoneco.2016.10.008.

Giudici, P., and A. Spelta. 2016. "Graphical Network Models for International Financial Flows." Journal of Business and Economic Statistics 34: 128-138.

Greenhill, Brian, and Yonatan Lupu. 2017. "Clubs of Clubs: Fragmentation in the Network of Intergovernmental Organizations." International Studies Quarterly 00: 1-16.

Haldane, Andrew. 2010. "The $\$ 100$ billion question." Comments at the Institute of Regulation and Risk, Hong Kong, Bank of England.

Hale, Galina. 2012. "Bank relationships, business cycles, and financial crises." Journal of International Economics 88: 312-325.

Hale, Galina, Tumer Kapan, and Camelia Minoiu. 2016. "Crisis Transmission through the Global Banking Network." Working Paper, Federal Reserve Bank of San Francisco.

Heipertz, Jonas, Romain Ranciere, and Natacha Valla. 2016. "Domestic and International Sectoral Portfolios: Network Structure and Balance Sheet Effects." unpublished.

Impavido, Gregorio, Heinz P. Rudolph, and Luigi Ruggerone. 2013. "Bank Funding in Central, Eastern and South Eastern Europe Post Lehman: A "New Normal"?" Working Paper, International Monetary Fund.

International Monetary Fund. 2016. "Financial Integration in Latin America." Staff Report. Jacomy, Mathieu, Tommaso Venturini, Sebastien Heymann, and Bastian Mathieu. 2014. "ForceAtlas2, a Continuous Graph Layout Algorithm for Handy Network Visualization Designed for the Gephi Software." PLOS One 9 (6): 1-12.

Katz, L. 1953. "A new status index derived from sociometric analysis." Psychometrika 18: $39-43$.

Kiyotaki, Nobuhiro, and John Moore. 2002. "Balance-Sheet Contagion." American Economic Review Papers and Proceedings 92: 46-50.

Klienberg, Jon M. 1999. "Authoritative sources in a hyperlinked environment." Journal of the ACM 46: 604-632.

Leicht, E. A., and M. E. J. Newman. 2008. "Community structure in directed networks." Physical Review Letters 100.

León, Carlos, and Jhonatan Pérez. 2013. "Authority Centrality and Hub Centrality as metrics of systemic importance of financial market infrastructures." Working Paper, Borradores de Economía. 
León, Carlos, Jhonatan Pérez, and Luc Renneboog. 2013. "A Multi-Layer Network of the Columbian sovereign securities market." In Analyzing the Economics of Financial Market Infrastructures, edited by Martin Diehl, Biliana Alexandrova-Kabadjova, Richard Heuver and Serafin Martinez-Jaramillo. IGI Global.

Lund, Susan, Toos Daruvala, Richard Dobbs, Philipp Harle, Ju-Hon Kwek, and Ricardo Falcon. 2013. "Financial globalization: Retreat or reset?" Global Capital Markets 2013, McKinsey Global Institute.

Mallaby, Sebastian. 2016. "Globalization Resets." Finance and Development 53: 6-10.

Martinez-Jaramillo, Serafin, Biliana Alexandrova-Kabadjova, Bernardo Bravo-Benitez, and Juan Pablo Solorzano-Margain. 2014. "An empirical study of the Mexican banking systemś network and its implications for systemic risk." Journal of Economic Dynamics and Control 40: 242-265.

Mayer, Thierry, and Soledad Zignago. 2011. "Notes on CEPII's distances measures: The GeoDist database." CEPII Working Paper.

Minoiu, Camelia, and Javier Reyes. 2013. "A network analysis of global banking: 19782010." Journal of Financial Stability 9: 168-184.

Newman, M. E. J. 2006. "Modularity and community structure in networks." Proceedings of the National Academy of Sciences 103: 8577-8582.

Newman, M. E. J., and M. Girvan. 2004. "Finding and evaluating community structure in networks." Physical Review E 69.

Papaioannou, Elias. 2009. "What drives international financial flows? Politics, institutions and other determinants." Journal of Development Economics 269-281.

Silva, J. M. C. Santos, and Silvana Tenreyro. 2006. "The Log of Gravity." The Review of Economics and Statistics 88 (4): 641-658.

von Peter, Goetz. 2007. "International banking centres: a network perspective." BIS Quarterly Review 4: 33-45.

Zhang, Xiao, Travis Martin, and M. E. J. Newman. 2015. "Identification of core-periphery structure in networks." Physical Review E 91 (032803). 